\begin{tabular}{|c|c|c|c|l|l|l|}
\hline \multirow{2}{*}{ LASER_LORos } & SYEN & syen_12106 & $\mathbf{Z}$ & Dispatch: September 15, 2014 & Journal: SYEN & CE: \\
\cline { 2 - 5 } \cline { 5 - 6 } & Journal Name & Manuscript No. & Author Received: & No of pages: 26 & TS: Naresh \\
\hline
\end{tabular}

Systematic Entomology (2014), 0, 0-0

DOI: $10.1111 /$ syen. 12106

\title{
Long-proboscid brachyceran flies in Cretaceous amber (Diptera: Stratiomyomorpha: Zhangsolvidae)
}

\author{
A NTONIO A R ILL O ${ }^{1}$, ENRIQUE P E N A L V E R ${ }^{2}$, R I C A R D O PÉREZ \\ - D E L A F UEN T E ${ }^{3}$, X AVIER DEL C L Ò S ${ }^{4}$, J U L I A C R I S C I O N E ${ }^{5}$, \\ PHILLIP M. B A R D N ${ }^{5}, M A R K L$. R I C C I O ${ }^{6}$ and D A V I D A. \\ G R I M A L D I ${ }^{5}$
}

\begin{abstract}
${ }^{1}$ Departamento de Zoología y Antropología Física, Facultad de Biología, Universidad Complutense, Madrid, Spain, ${ }^{2}$ Museo Geominero, Instituto Geológico y Minero de España, Madrid, Spain, ${ }^{3}$ Museum of Comparative Zoology, Harvard University, Cambridge, MA, U.S.A., ${ }^{4}$ Departament d'Estratigrafia, Paleontologia i Geociències Marines, Facultat de Geologia, Universitat de Barcelona, Barcelona, Spain, ${ }^{5}$ Division of Invertebrate Zoology, American Museum of Natural History, New York, NY, U.S.A. and ${ }^{6}$ Institute of Biotechnology, Cornell University, Ithaca, NY, U.S.A.
\end{abstract}

\begin{abstract}
The monophyletic family Zhangsolvidae comprises stout-bodied brachyceran flies with a long proboscis and occurring only in the Cretaceous, originally known in shale from the Early Cretaceous Laiyang Formation (Fm.) in China (Zhangsolva Nagatomi \& Yang), subsequently from limestones of the Early Cretaceous Crato Fm. of Brazil. Cratomyoides Wilkommen is synonymized with Cratomyia Mazzarolo \& Amorim, both from the Crato Fm.; Cratomyiidae is synonymized with Zhangsolvidae. Two genera and three species of Zhangsolvidae are described: Buccinatormyia magnifica Arillo, Peñalver \& Pérez-de la Fuente, gen. et sp.n. and B. soplaensis Arillo, Peñalver \& Pérez-de la Fuente, sp.n., in Albian amber from Las Peñosas Fm. in Spain; and Linguatormyia teletacta Grimaldi, gen. et sp.n., in Upper Albian-Lower Cenomanian amber from Hukawng Valley in Myanmar. Buccinatormyia soplaensis and Linguatormyia teletacta are unique among all Brachycera, extant or extinct, by their remarkably long, flagellate antennae, about 1.6x the body length in the latter species. A phylogenetic analysis of 52 morphological characters for 35 taxa is presented, 11 taxa being Cretaceous species, which supports placement of the family within Stratiomyomorpha, although not to any particular family within the infraorder.
\end{abstract}

This published work has been registered in Zoobank, http://zoobank.org/urn:lsid: zoobank.org:pub:F32CF887-7C37-45D5-BD6B-135FE9B729A7.

\section{Introduction}

The Zhangsolvidae is an extinct family of brachyceran flies erected by Nagatomi \& Yang (1998) for Zhangsolva cupressa (Zhang, Zhang \& Li), preserved in shale from the Early Cretaceous of China. The family was subsequently found to include two species of Cratomyia from the Aptian-aged Crato

Correspondence: Ricardo Pérez-de la Fuente, Museum of Comparative Zoology, Harvard University, 26 Oxford St., Cambridge, MA 02138, U.S.A. E-mail: perezdelafuente@fas.harvard.edu

The authors declare no conflict of interest.
Formation limestone of Brazil (Mazzarolo \& Amorim, 2000; Wilkommen \& Grimaldi, 2007). The genus Cratomyia was placed in the infraorder Stratiomyomorpha by Mazzarolo \& Amorim (2000), a basal lineage of Brachycera that includes three living families: the Stratiomyidae Latreille, a cosmopolitan group comprising 2651 species in 375 genera (Woodley, 2001); the Xylomyidae Verrall, a small cosmopolitan family comprising approximately 138 species in four genera (Woodley, 2011); and the Pantophthalmidae Bigot, a small neotropical family of very large flies with 20 species in two genera (Val, 1976). Several other late Mesozoic families have been suggested to be within this infraorder, but their relationships remain poorly understood. These families include 
Eremochaetidae Ussatchov, Tethepomyiidae Grimaldi \& Arillo and, perhaps, Oligophrynidae Rohdendorf (Krzemiński \& Krzemińska, 2003; Grimaldi \& Arillo, 2008), although the focus of this paper is on the position of Zhangsolvidae.

In this paper we describe four new Cretaceous specimens of Zhangsolvidae, three of them originally found in the same amber piece from the Spanish locality of El Soplao, plus one specimen from Burmese amber. The El Soplao outcrop, Albian in age, was recently discovered in Spain (Najarro et al., 2009, 2010; Peñalver \& Delclòs, 2010). To date, insects belonging to 13 orders and about 40 families are preserved in this amber (Pérez-de la Fuente, 2012). In the order Diptera, the families Atelestidae, Cecidomyiidae, Ceratopogonidae, Chimeromyiidae, Chironomidae, Dolichopodidae, Hybotidae, Phoridae, Psychodidae and Rhagionidae have been found (ibid.), although only ceratopogonids have been studied (Pérez-de la Fuente et al., 2011).

Burmese amber contains probably the most diverse palaeobiota of the seven major world deposits of amber from the Cretaceous Period, with approximately 228 families of organisms (primarily arthropods) thus far reported, Diptera being especially diverse (Zherikhin \& Ross, 2000; Grimaldi et al., 2002; Ross et al., 2010). Burmese amber contains, for instance, the oldest definitive Mesozoic record of mosquitoes (Culicidae) (Borkent \& Grimaldi, 2004). Estimated age of 'burmite' was recently established as the Albian-Cenomanian boundary, $c$. $99 \mathrm{Ma}$, based on radiometric dating of zircons from the amber matrix (Shi et al., 2012).

The new zhangsolvids are the first specimens preserved as amber inclusions and the youngest occurrences in the fossil record of the family, significantly expanding its palaeobiogeographic range. The exquisite preservation in amber allows observation of minute morphological details, providing substantially more data to test the proposed relationships of Zhangsolvidae within the Stratiomyomorpha. These findings also provide significant palaeoecological data, but these are presented elsewhere (E. Peñalver et al., in preparation).

\section{Material and methods}

The Spanish specimens were discovered in a large piece of amber containing numerous inclusions from the El Soplao outcrop, near the municipality of Rábago (Autonomous Community of Cantabria). This piece was trimmed into several smaller pieces to better allow examination of individual inclusions. Each of these smaller pieces was embedded in synthetic resin (EPO-TEK 301) and then polished (see Nascimbene \& Silverstein, 2000). Fossils were examined with an Olympus BX51 compound microscope. Photomicrographs were taken using an attached camera, some of them z-stacked. Drawings were made using an Olympus U-DA drawing tube attached to the compound microscope. The Spanish specimens are provisionally housed at the Museo Geominero (IGME) in Madrid (Spain); their final deposit will be in the collection of the El Soplao Cave (Government of Cantabria). The Burmese amber specimen is in the American Museum of Natural History, New York, and was purchased in 2012 from Mr. Sieghard Ellenberger, Germany, who obtained the amber from mines near Myitkyina, Kachin Province, northern Myanmar (see Grimaldi et al., 2002). The amber surfaces lying over the dorsal and ventral portions of the fly were slightly flattened using a lapidary wheel; there was no other preparation. The amber piece is occluded with a turbid suspension of particles, so in order to visualize critical details it was CT scanned at the Cornell Biotechnology Resource Center Imaging Facility.

The Burmese specimen scanning was performed using a Zeiss VERSA XRM-520 instrument. For each dataset, 2400 X-Ray projections were obtained at $0.15^{\circ}$ intervals over $360^{\circ}$ using $60 \mathrm{kV}, 32 \mu \mathrm{A}$ and $5000 \mathrm{~ms}$ exposure time, with a $2048 \times 2048$ pixel detector using a $1.5 \mu \mathrm{m}$ pixel size that was $2 \times 2$ binned into an effective pixel size of $3.0 \mu \mathrm{m}$. Proper placement of the specimen was accomplished with the assistance of X-Ray fluoroscopy mode, to ensure that the area of interest was included within the scanning field of view. The projection views were used to reconstruct a CT image using a convolution back-projection approach implemented in $3 \mathrm{D}$, giving a $3 \times 3 \times 3 \mathrm{~mm}$ volume of image data with $3 \mu \mathrm{m}$ isotropic voxels in arbitrary density units (ADU) and exported as DICOM or TIEF stacks. Reconstructed data files were imported into the software programs OsiriX (64 bit, v5.5) and Avizo 8.0 (VSG), where they were visualized and analysed using a variety of $2 \mathrm{D}$ and $3 \mathrm{D}$ techniques.

Fly morphological terminology generally follows McAlpine (1981). We do not use the term postpedicel, used by some dipterists to refer to that portion of the antenna distal to the pedicel, because by definition this is the flagellum. Szucsich \& Krenn $(2000,2002)$ introduced the term ventral rostral membrane, which we use here, referring to the pleated membrane at the base of the proboscis.

Although the three Spanish amber specimens are syninclusions, the gender of only one of them is definitive. Because another specimen is substantially larger but lacks terminalia (and has significant differences in venation and antennal structure), the lengths of the thorax and wing in 34 exemplar extant species of Stratiomyidae, Xylomyidae and Pantophthalmidae were measured for at least one male and one female, to test for the presence/extent of sexual dimorphism in body size. We used pinned specimens from the AMNH collection for these measurements. For the first two of these families the measurements were made using a Nikon SMZ1500 stereomicroscope and NIS Elements software; measurements of Pantophthalmidae were made using a millimetre ruler because of their large sizes.

Phylogenetic analysis used morphological characters from exemplar extant and fossil stratiomyomorphans, as well as all species of Zhangsolvidae, analysed under equal-weights parsimony with the program TNT (Goloboff et al., 2008). Parameters employed an 'XMULT' search, which uses sectorial searching, tree drifting, ratcheting and fusing. The search ran until the optimal tree score was found $100 \times$ independently, whereupon all lowest-cost topologies were consolidated into a strict consensus. Consistency and retention indices were calculated, along with Bremer and bootstrap support values (with 10000 pseudoreplicates). 


\section{Systematic palaeontology}

Order Diptera Linnaeus, 1758

Infraorder Stratiomyomorpha Hennig, 1973

\section{Family Zhangsolvidae Nagatomi \& Yang, 1998}

Cratomyiidae Mazzarolo \& Amorim, 2000: 94. Type genus and species: Cratomyia macrorrhyncha Mazzarolo \& Amorim (by original designation). NEW SYNONYMY.

Type genus and species. Zhangsolva Nagatomi \& Yang, 1998. Holotype of the type species Archisolva cupressa Zhang, Zhang \& Li, 1993, is currently lost (Dr H.-C. Zhang, personal communication to A.A., 2011). Archisolva was preoccupied in Stratiomyidae, so Nagatomi \&Yang 1998 provided the replacement generic name Zhangsolva.

Taxonomic composition. Zhangsolva cupressa (Zhang et al., 1993); Cratomyia macrorrhyncha Mazzarolo \& Amorim, 2000; Cratomyia cretacica (Wilkommen, 2007), comb.n.; Buccinatormyia magnifica Arillo, Peñalver \& Pérez-de la Fuente, gen. et sp.n.; Buccinatormyia soplaensis Arillo, Peñalver \& Pérez-de la Fuente, sp.n.; Linguatormyia teletacta Grimaldi gen. et sp.n.

Diagnosis (emended). Proboscis rather long to very long (from 1 to about $4 \times$ the head length), slender, apex with small labellum; vein $\mathrm{C}$ ending at or near apex of wing, $\mathrm{M}_{1}$ strongly arched, $\mathrm{M}_{3}$ fused to $\mathrm{CuA}_{1}$ and $\mathrm{CuA}_{2}$ fused to $\mathrm{A}_{1}$ near wing margin.

Remarks. We have refrained from including the following characters in the family diagnosis above, as they are not known from all the zhangsolvid genera (only from half or less of the species, mainly the ones preserved in amber), but we posit that they could be of importance to characterize the family: (i) maxillary palp two-segmented, long and projecting (observed in Buccinatormyia magnifica gen. et sp.n. and Linguatormyia teletacta gen. et sp.n., tentatively observed in Cratomyia macrorrhyncha, see Mazzarolo \& Amorim, 2000), (ii) tibial spurs 0, 2, 2 (only observed in B. magnifica), and (iii) pulvilli and empodium well developed, pulvilliform (idem). Some zhangsolvids, i.e. Buccinatormyia soplaensis sp.n. and L. teletacta, are readily recognizable by showing remarkable flagellate antennae that can be more than $1.5 \times$ longer than the body (in the latter species).

The species Archisolva cupressa was described by Zhang et al. (1993) from the Early Cretaceous Laiyang Formation in Laiyang, Shandong Province, China, originally placed in the family Solvidae (=Xylomyidae). Later, Nagatomi \& Yang (1998) proposed a replacement name, as the generic name was already occupied by Archisolva Enderlein (Stratiomyidae). They provided the new name Zhangsolva and considered that, even though the genus was close to Stratiomyoidea, it represented a new family. Diagnostic characters of the new family Zhangsolvidae proposed by Nagatomi \& Yang (1998) were: (i) long basal section of Rs, (ii) antennal flagellum 12-segmented,

(iii) proboscis conspicuously long and (iv) costal cell concave before Rs, possibly representing a sc-r crossvein. The holotype was not studied by Nagatomi \& Yang, so they assumed that the original illustrations were accurately drawn. Unfortunately, the holotype of $Z$. cupressa (a unique specimen) is currently lost ( $\mathrm{Dr}$ H.-C. Zhang, personal communication to A.A., 2011), which is why we were unable to restudy the holotype. According to the ICZN code, dramatic taxonomic changes would be necessary for the designation of a new type specimen of the family (from a different type genus), which we have not made in case the lost specimen eventually appears in a Chinese collection, or a new specimen (and potential neotype) is excavated from the Laiyang Formation.

Later, Mazzarolo \& Amorim (2000) described Cratomyia macrorrhyncha, from the Early Cretaceous Crato Formation, Brazil, for which they proposed the family Cratomyiidae. Their study revealed that Cratomyia was a sister group to (Xylomyidae + Stratiomyidae), but these authors had not taken into account Zhangsolva cupressa. The most recent contribution on this group of flies was the description of Cratomyoides cretacicus Wilkommen (in Wilkommen \& Grimaldi, 2007), a fossil fly also found in the Crato Formation and very similar to Cratomyia. In that paper the authors recognized the close relationship among Zhangsolva, Cratomyia and Cratomyoides. Recently, Grimaldi et al. (2011) suggested that all of these fossils should be included in the family Zhangsolvidae (with Cratomyiidae as a junior synonym). They also suggested that Cratomyoides is a junior synonym of Cratomyia, but they did not formally synonymize these taxa. In the same work the authors also indicated that several features in the original description of Zhangsolva were probably erroneous: (i) parts of the wing venation are obvious artefacts, such as a sc-r crossvein, which is present in only one wing (as seen in the photograph of the holotype in the original paper), and (ii) the antennae probably have no more than eight flagellomeres (the groundplan in Brachycera), a misinterpretation perhaps originating from preservation (e.g. transverse cracks in carbonaceous films commonly occur in compression-fossil insects preserved in rock). Furthermore, the long basal section of Rs proposed as diagnostic for Zhangsolvidae for Nagatomi \& Yang (1998) is quite short in the new Burmese amber species. Hence, the conspicuously long proboscis is the only character that we have retained here from the original diagnosis of the family.

\section{Genus Cratomyia Mazzarolo \& Amorim}

Cratomyia Mazzarolo \& Amorim, 2000: 94. Type species: C. macrorrhyncha Mazzarolo \& Amorim. By original designation.

Cratomyoides Wilkommen, 2007, in Wilkommen \& Grimaldi, 2007: 375. Type species: Cratomyoides cretacicus Wilkommen. By original designation. NEW SYNONYMY.

Diagnosis (emended). Cratomyia is readily separated from other (Laurasian) genera of Zhangsolvidae by the unique presence in the former of a stem to veins $\mathrm{M}_{1}$ and $\mathrm{M}_{2}$ distal to cell $\mathrm{d}$ (instead of diverging directly from cell d). 


\section{Genus Buccinatormyia Arillo, Peñalver \& Pérez-de la Fuente, gen. $n$ \\ http://zoobank.org/urn:lsid:zoobank.org:act:D45D7DD7- 89E2-450F-BA5E-46F92F66611A}

\section{Type species. Buccinatormyia magnifica sp.n.}

Etymology. Derived from buccinator- (L.), trumpeter, and -myia (Gr.), fly, in reference to the long proboscis.

Diagnosis. Antenna with six articles (four flagellomeres), with minute apical stylus; stem of Rs long (several times the r-m crossvein length), $\mathrm{C}$ vein ending beyond $\mathrm{R}_{5}$ but without reaching $M_{1}$, veins $M_{1}$ and $M_{2}$ diverging directly from cell $d$ (not from a portion of $\mathrm{M}_{1+2}$ distad to cell $\mathrm{d}$ ).

\section{Buccinatormyia magnifica Arillo, Peñalver \& Pérez-de la Fuente, sp. $n$ \\ http://zoobank.org/urn:lsid:zoobank.org:act:21A4E7D7-D8F6- 4FBB-9736-73F5F80F6066}

(Figs 1-8)

Type material. Holotype CES-349.1 and paratype in two parts, CES-015.1 and CES-392.3, from El Soplao amber (Spain). These specimens and holotype of B. soplaensis sp.n. were found in the same amber piece as syninclusions, which was prepared in three sample pieces for study (CES-349: amber fragment $10 \times 5 \times 5 \mathrm{~mm}$ in a resin prism $16 \times 8 \times 5 \mathrm{~mm}$; CES-015: amber fragment $13 \times 11 \times 6 \mathrm{~mm}$ in a resin trapezoid $15 \times 19 \times 6 \mathrm{~mm}$; and CES-392: amber fragment $24 \times 10 \times 7 \mathrm{~mm}$ in a resin prism $30 \times 11 \times 8 \mathrm{~mm}$ ). Holotype is in a good state of preservation, virtually complete, but wings are incomplete and a dorsal portion of the thorax is slightly altered. Also, proboscis, legs and abdomen are crossed by a fracture that partially destroyed some small portions of the abdomen. Paratype is strongly compressed but virtually complete, lacking only the distal portions of the proboscis and the abdomen; it lies in two prepared sample pieces, the smaller portion (CES-392.3) consisting of a costal fragment of wing with the halter, several leg portions and a small portion of the abdominal cuticle.

Syninclusions. Holotype and paratype of the new species and the holotype of B. soplaensis sp.n. were preserved in one large piece of amber, which was divided into several pieces to allow study of the 48 arthropods in it, including ten additional dipterans, mainly small brachycerans.

Etymology. Named after the wonderful state of preservation and the impressive habitus of the two specimens.

Diagnosis. Proboscis very elongate (about $0.40 \times$ the body length); antenna not flagellate and short (about $0.30 \times$ the wing length), flagellomere II with dorsal surface concave, flagellomere III about $0.30 \times$ the antennal length; Sc ending at level of $\mathrm{r}-\mathrm{m}$ crossvein, cell $\mathrm{m}_{3}$ narrow $(\mathrm{W} / \mathrm{L}=0.21), \mathrm{M}_{2}$ and $\mathrm{M}_{3}$ nearly parallel, $\mathrm{CuP}$ well sclerotized.

Description (\%; based largely on the holotype except for wing features entirely based on the paratype). Body $9.20 \mathrm{~mm}$ long (estimated from reconstruction).

Head: Broad, $1.82 \mathrm{~mm}$ wide. Eyes large, bulging, occupying nearly entire lateral surface of head (genae exposed ventrally), widely separated, ventrally $0.73 \mathrm{~mm}$ wide between inner margins; bare, devoid of interfacetal setulae; facets undifferentiated; inner margins in frontal view without emargination around antennal base. Eyes significantly broader dorsally. Dense, long, fine, stiff setae around eye margin. Three small ocelli present, lying in a clearly demarcated, densely setose ocellar triangle. Vertex of head with paramedian emarginations, centrally raised into median dorsal tubercle; vertex with three ranges of pilosity: (i) vestiture of fine, dense setulae as on the rest of the head, (ii) sparse, longer setae, and (iii) long, fine, stiff setae like those around eye margin. Areas surrounding antennal bases raised into bare, rounded mounds (=facial lobes), nearly meeting medially. Front of head with well-developed, inverted Y-shaped sulcus. Clypeus large, bulging, covered by fine, dense setulae, raised into low mound between facial lobes and palpal bases, fully frontal in position; with short vertical and median sulci and a transverse, median depression; ventral surface of clypeus membranous, oval; membrane connected to base of proboscis. Frontoclypeal sulci (demarcating lateral edges of clypeus) very deep. Genae developed into pair of rounded, ventral lobes. Neck entirely membranous.

Proboscis: Long (virtually all of it haustellum), $3.85 \mathrm{~mm}$ long from base to apex $(0.42 \times$ the body length), $0.05 \mathrm{~mm}$ wide, $0.17 \mathrm{~mm}$ high at middle. Proboscis laterally flattened, $0.05 \mathrm{~mm}$ wide, $0.17 \mathrm{~mm}$ high at the middle (width $0.31 \times$ the cross-sectional depth) and directed forward in relation to head. Proboscis inserted below facial margin. Base of proboscis ventrally with annulated membrane (ventral rostral membrane), five-folds visible, each with numerous annulations (membrane probably telescoped). Proboscis covered by dense microtrichia and a dense vestiture of large, stiff deeply-ribbed setae with stellate transverse section and directed forward. Haustellum externally composed by a tube-like structure with a dorsal groove (=theca), subellipsoidal in cross-section and with straight lateral walls (well preserved in holotype; laterally collapsed in paratype, ventrally forming an artifactual surface). Dorsal groove internally closed by a narrow (0.05-mm wide), semitransparent membrane with thickened margins and covered dorsally by a fine vestiture of minute setae, interpreted as a modified labrum (most visible in the basal half of the holotype's proboscis, partially broken and protruding due to downward bending of the proboscis). Labrum externally covering the proboscis base and basally entering into the proboscis. Epi/hypopharynx not visible, but most likely forming floor of proboscis. Food canal preserved, $0.03 \mathrm{~mm}$ wide and $0.07 \mathrm{~mm}$ high as preserved) (visible in the amber surface that cross-sections the paratype's proboscis). Labellum very small, about as wide as proboscis, oval in cross-section. Labellar lobes closely pressed together 


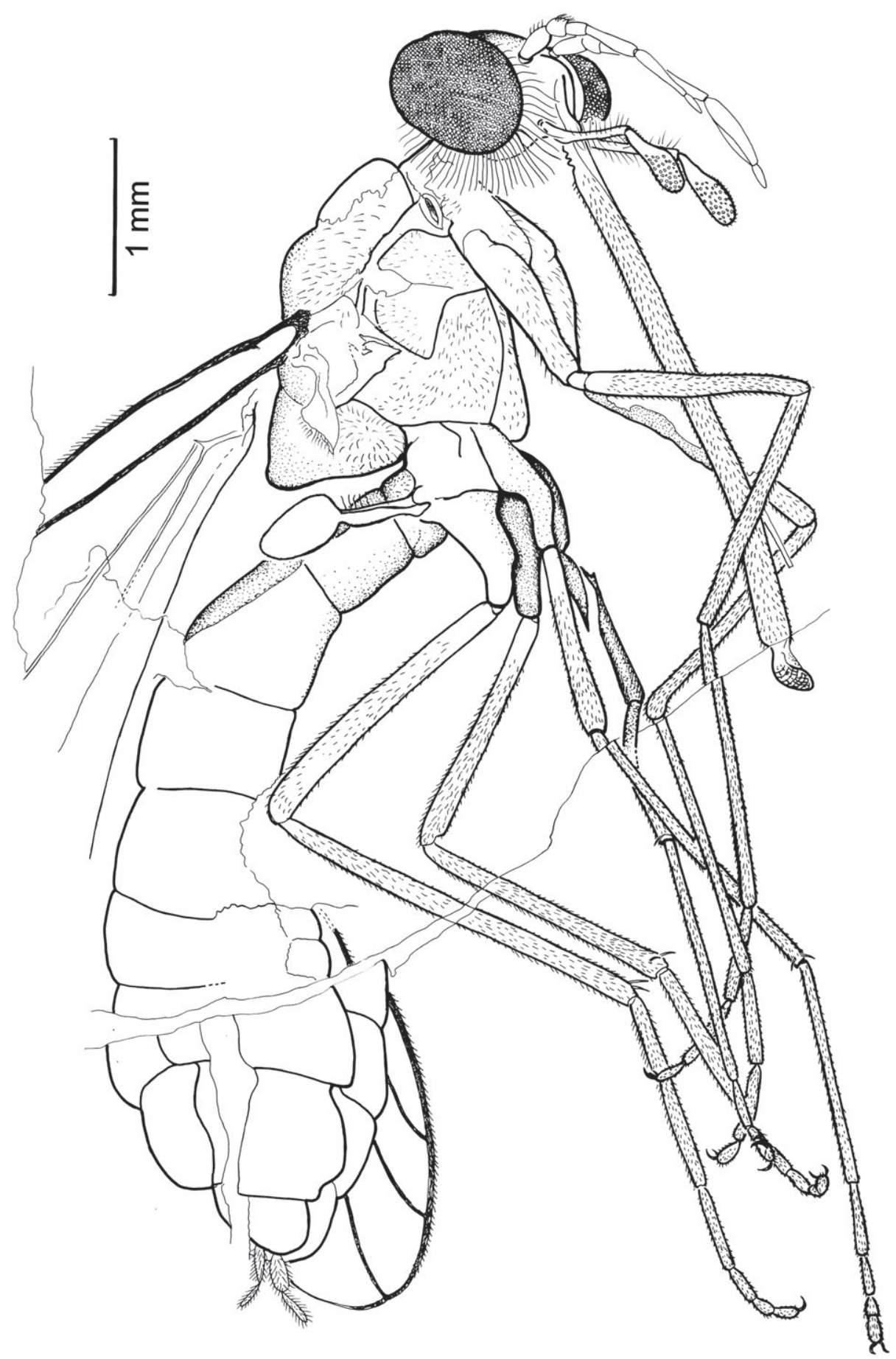

Fig. 1. Buccinatormyia magnifica gen. et sp.n., from El Soplao amber. Entire holotype CES-349.1 (ventro-oblique view), shown as preserved.

medially, $0.22 \mathrm{~mm}$ long, $0.13 \mathrm{~mm}$ high; each lobe has around 13 pseudotracheae with transverse pseudotracheal rings on exposed surfaces.

Maxillary palp: Elongate, $1.45 \mathrm{~mm}$ long; projected forward; two-segmented. Bases of palps flank base of proboscis. Basal palpomere straight and long, $0.60 \times$ the total palp length; inflated basally and gradually narrowing distally, $0.15 \mathrm{~mm}$ high at the base (greatest height), $0.06 \mathrm{~mm}$ high at apex (lowest height); distal $2 / 3$ of its length laterally flattened, $0.11 \mathrm{~mm}$ wide at the base (greatest width). Basal palpomere with abundant, very long, fine, stiff setae along its length, oriented at $90^{\circ}$-angle to the antennal axis. Apical palpomere long, club-like, pedunculate, 


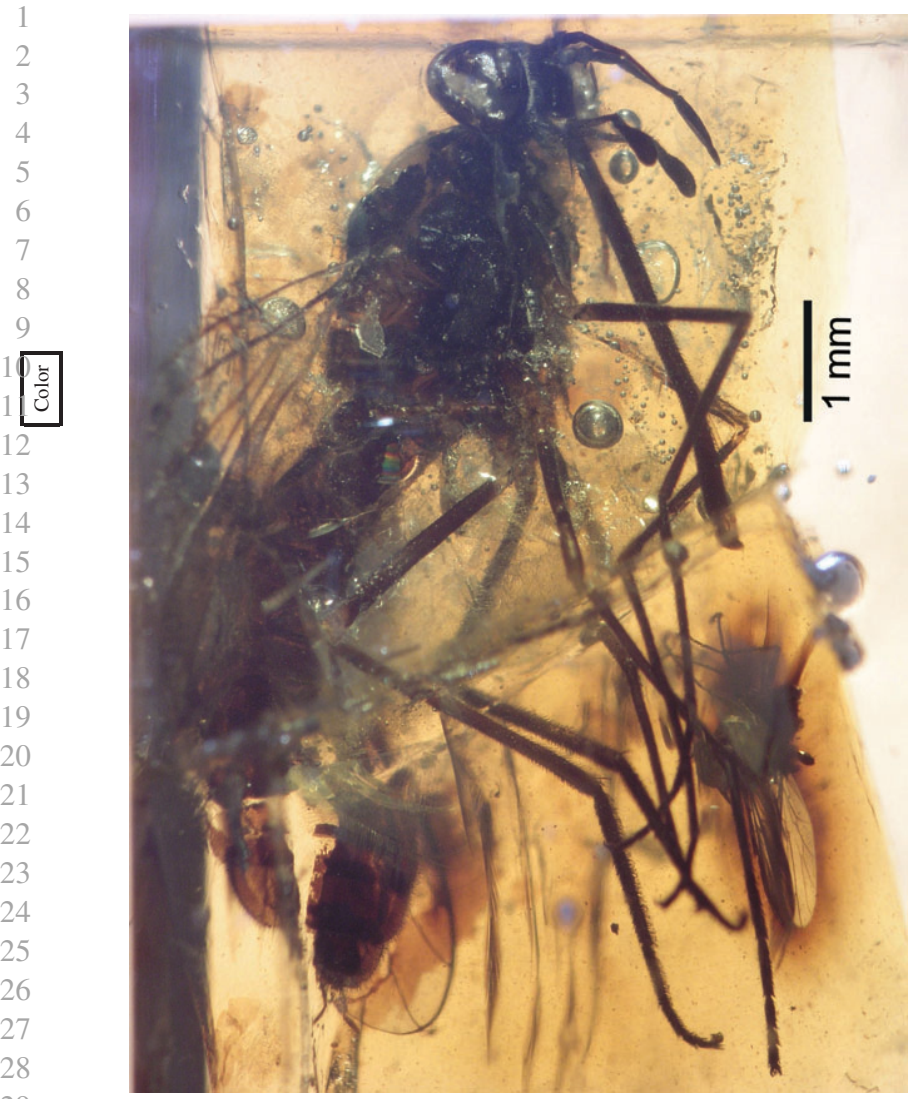

Fig. 2. Buccinatormyia magnifica gen. et sp.n., from El Soplao amber. Photomicrograph of the holotype, CES-349.1.

strongly laterally flattened, very broad distally, apex rounded; with several fine foveae (probably sensilla) distributed mainly distally but without apparent pattern.

Antenna: Six-articled (flagellum with four flagellomeres), projecting forward; $1.85 \mathrm{~mm}$ long $(0.20 \times$ estimated body length). Antennal bases narrowly separated by distance subequal to diameter of antennal socket (c. $0.80 \times$ distance between palp bases). Scape short, $c$. twice as long as wide, $0.18 \mathrm{~mm}$ long, $0.10 \mathrm{~mm}$ wide, $0.14 \mathrm{~mm}$ high; both scapes oriented anterolaterally (divergent) as preserved. Scape and pedicel covered by sparse, relatively strong setae projected forward. Antenna entirely covered by a vestiture of dense, fine setulae. Pedicel short, $0.75 \times$ the scape length, as wide as scape. Flagellum relatively short, laterally flattened, comprising four flagellomeres: I $0.27 \mathrm{~mm}$ long, $0.06 \mathrm{~mm}$ wide, $0.09 \mathrm{~mm}$ high, approximately as long as scape + pedicel; $\mathrm{II} 0.56 \mathrm{~mm}$ long, $0.05 \mathrm{~mm}$ wide, $0.09 \mathrm{~mm}$ high (greatest height); III as long as flagellomere II but with different morphology, $0.53 \mathrm{~mm}$ long, $0.12 \mathrm{~mm}$ wide (greatest width), $0.03 \mathrm{~mm}$ high; IV short, as long as scape, $0.18 \mathrm{~mm}$ long, $0.03 \mathrm{~mm}$ wide, $0.06 \mathrm{~mm}$ high (greatest height). Flagellomere II with dorsal surface concave; II and III inserted ventrally to their proximal flagellomere. Flagellomere III proximally with a few fine foveae (probably sensilla), similar to those on distal palpomere, distribution without apparent pattern; this flagellomere with narrow band on ventrolateral surface (except on apex) comprising dense, small foveae (probably sensilla much smaller than other foveae on antenna and palp). Flagellomere IV acuminate distally. Antenna with minute apical stylus.

Thorax: Narrow and deep as preserved, $2.34 \mathrm{~mm}$ long, $1.20 \mathrm{~mm}$ wide (estimated), $1.88 \mathrm{~mm}$ high, slightly narrower than head (thoracic cuticle of holotype partially lost, mainly anterodorsally; thorax of paratype slightly collapsed, pleuron not well seen). Thorax devoid of macrosetae, exocuticle with fine, short setae only; coloration appears uniformly dark brownish (possibly preservational). Anterior part of thorax obscure. Mesothorax large, expansive. Katepisternum ventrally broad and slightly bulging. Anepisternum large; anepimeron smaller, subdivided by partial cleft; mesothoracic spiracle not visible; meron slightly larger than mesocoxa. Coxa and ventral surfaces of femur with sparse, short setulae. Procoxa slender, $1.02 \mathrm{~mm}$ long; mesocoxa $0.64 \mathrm{~mm}$ long, $0.23 \mathrm{~mm}$ wide basally; metacoxa $0.60 \mathrm{~mm}$ long. Anterodistal surfaces of each coxa with small, protruding lobe. Trochanter small, slender, fully articulated with femur and coxa (no fusion). Legs slender. Prothoracic leg about as long as other legs: femur $1.58 \mathrm{~mm}$ long, tibia $1.63 \mathrm{~mm}$ long and tarsomere $\mathrm{I} 2.38 \mathrm{~mm}$ long. Mesothoracic leg $5.85 \mathrm{~mm}$ long, as estimated: femur $1.70 \mathrm{~mm}$ long as estimated, tibia $1.95 \mathrm{~mm}$ long, tarsomere (ta) I $1.22 \mathrm{~mm}$ long, taII $0.45 \mathrm{~mm}$ long, taIII mm 0.23 long, taIV $0.13 \mathrm{~mm}$ long and taV $0.18 \mathrm{~mm}$ long. Metathoracic leg $6.83 \mathrm{~mm}$ long: femur $2.03 \mathrm{~mm}$ long, tibia $2.50 \mathrm{~mm}$ long, tarsomere (ta) I $1.30 \mathrm{~mm}$ long, taII $0.48 \mathrm{~mm}$ long, taIII $0.25 \mathrm{~mm}$ long, taIV $0.13 \mathrm{~mm}$ long and taV $0.15 \mathrm{~mm}$ long. Femora with recumbent, dense setulae. Tibiae with denser, stronger setae. Protibia without spurs. One pair of setose distal spurs each on meso- and metatibia. Tarsomeres covered with abundant, short, strong setae. Tarsi more setose than tibiae, especially strong setae distally and each tarsomere having several distal, spine-shaped setae. Claws covered by microtrichia. Pulvilli paddle-shaped; flat, paddle-shaped (pulvilliform) empodia on all pretarsi, of similar size to pulvilli; all three pads covered by microtrichia.

Wing (based on paratype, including halter): Length $6.00 \mathrm{~mm}$, $2.09 \mathrm{~mm}$ wide (greatest width) (W/L=0.35). Costal vein ending between $R_{5}$ and $M_{1}$. Veins $S c$ and $R$ fused basally to crossvein h; Sc $2.57 \mathrm{~mm}$ long $(0.43 \times$ the wing length). Vein Sc meets wing margin beyond middle of wing length, at level of vein $\mathrm{r}-\mathrm{m}$. Vein $\mathrm{R}_{1} 3.15 \mathrm{~mm}$ long, gradually thickened apically; stem of Rs relatively long, $0.89 \mathrm{~mm}$ long (ca. $4.5 \times$ the length of $\mathrm{r}-\mathrm{m}$ crossvein); $\mathrm{R}_{2+3} 1.62 \mathrm{~mm}$ long; stem of $\mathrm{R}_{4+5}$ $1.51 \mathrm{~mm}$ long, $\mathrm{R}_{4}$ and $\mathrm{R}_{5}$ short, asymmetrical, $\mathrm{R}_{4} 0.57 \mathrm{~mm}$ long, $\mathrm{R}_{5} 1.05 \mathrm{~mm}$ long; tip of $\mathrm{R}_{5}$ preapical to wing tip. Cell $\mathrm{d}$ short and thick, $1.03 \mathrm{~mm}$ long (greatest length), $0.40 \mathrm{~mm}$ wide $(\mathrm{W} / \mathrm{L}=0.39)$. Stem of $\mathrm{M}_{1+2} 0.86 \mathrm{~mm}$ long; $\mathrm{M}_{1}$ arched costad, tip of $\mathrm{M}_{1}$ ending posterior to wing tip; $\mathrm{M}_{1} 1.18 \mathrm{~mm}$ long (linear, not along curvature), $\mathrm{M}_{2} 0.74 \mathrm{~mm}$ long; $\mathrm{M}_{1}$ and $\mathrm{M}_{2}$ diverge directly from cell $\mathrm{d}$, not from a portion of $\mathrm{M}_{1+2}$ distad to cell $d$; veins $M_{2}$ and $M_{3}$ nearly parallel. $M_{2}$ ends before wing margin. Cell $\mathrm{m}_{3}$ long and slender, $1.02 \mathrm{~mm}$ long, $0.21 \mathrm{~mm}$ wide $(\mathrm{W} / \mathrm{L}=0.21)$; veins $\mathrm{CuA}_{1}$ and $\mathrm{M}_{3}$ joined in very short vein before meeting wing margin. Cell br slightly narrower than bm; cell bm slightly longer $(2.72 \mathrm{~mm}$ long, vs. $2.54 \mathrm{~mm}$ ). Vein $\mathrm{CuA}$ with base approximately half the thickness 


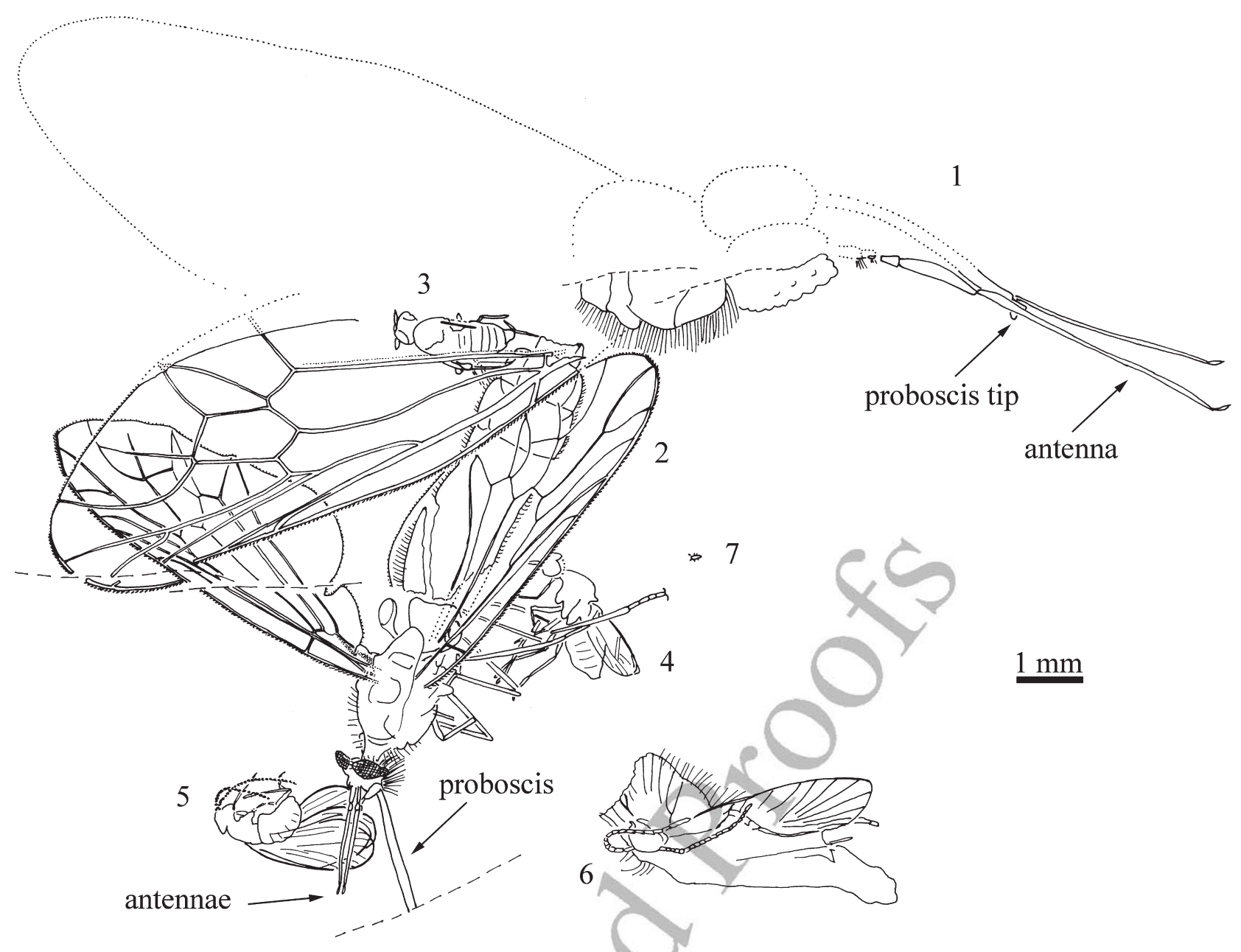

Fig. 3. Spatial relation of the paratype of Buccinatormyia magnifica gen. et sp.n., the holotype of B. soplaensis sp.n., and some other close syninclusions integrating drawings from two preparations of the same amber piece (CES-015 and CES-392). (1) Buccinatormyia soplaensis partially reconstructed; (2) Buccinatormyia magnifica; (3-4) Diptera: Brachycera; (5) Neuroptera: Coniopterygidae; (6) Lepidoptera: Micropterigidae; (7) Acari: Actinedida.

of base of $\mathrm{R} ; \mathrm{CuA}_{2}$ fusing with $\mathrm{A}_{1}$ prior to wing margin, forming closed, narrow cell cup; cup $2.97 \mathrm{~mm}$ long $(\mathrm{W} / \mathrm{L}=0.12) ; \mathrm{CuP}$ well developed and sclerotized, parallel to $\mathrm{CuA}$ and separated by distance equal to vein thickness. Vein $\mathrm{CuA}_{2}$ strongly curved before connection with $\mathrm{A}_{1}$. Vein $A_{1}$ entirely straight; $A_{2}$ preserved, basal sclerotized portion $0.95 \mathrm{~mm}$ long. Apices of veins $\mathrm{CuA}_{1}+\mathrm{M}_{3}$ and $\mathrm{CuA}_{2}+\mathrm{A}_{1}$ very thin, faint. Anal lobe, alula and calypter well developed; calypter $0.52 \mathrm{~mm}$ long, with marginal vein. Wing membrane entirely hyaline (no patterning or pterostigmatic sclerotization), evenly covered with minute microtrichia. Halter $1.00 \mathrm{~mm}$ long, with slender apical knob $0.41 \mathrm{~mm}$ long, $0.21 \mathrm{~mm}$ wide. Stem and knob covered by dense microtrichia and knob with a few additional longer setae. Halter with sensory area at least in middle of its stem, having campaniform-like sensilla; pilosity of base obscure.

Abdomen (virtually complete in holotype): Broad, broader distally, $1.45 \mathrm{~mm}$ wide (greatest width), slightly broader than thorax; $5.30 \mathrm{~mm}$ long (without cerci); strongly flattened dorsoventrally, especially on margins. Abdomen comprising eight visible segments; dorsal surface (tergites) flat, virtually without relief. Coloration appears uniformly dark brownish (possibly preservational). Sternites cover entire transverse width of abdomen; no abdominal pleural membrane exposed. Segments V-VIII laterally form very thin planar expansions (='lateral flanges' sensu Stuckenberg (2000) for Vermileonidae), but very small on segment VIII; segment IV apparently with a small distal section as lateral flanges. Abdominal cuticle showing a vestiture constituted by two different types of specialized setae: (i) 'stellate hairs', corresponding to microtrichia arranged in bunches of $c$. five, present on dorsal surface of lateral flanges and also laterally at least on segment III, and (ii) large, stiff deeply-ribbed setae (stellate in transverse section), similar to those on proboscis, sparsely covering the entire abdominal cuticle. Only larger lateral flanges (segments $\mathrm{V}-\mathrm{VII}$ ) have dorso-marginal, 


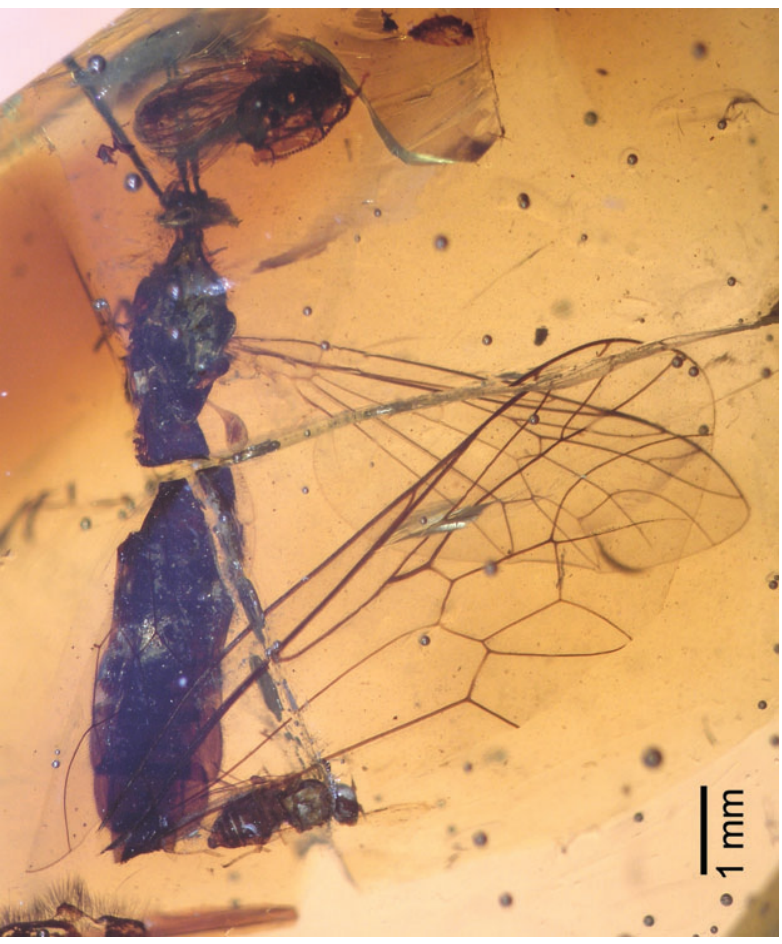

Fig. 4. Photomicrograph of the paratype of Buccinatormyia magnifica gen. et sp.n. and the wing of the holotype of B. soplaensis sp.n., CES-015.

longitudinal, curved lines comprising minute ellipsoid plaques of variable size (=abdominal muscle plaques, see Stoffolano et al., 1988). Female terminalia preserved: cercus strongly flattened dorsoventrally, two-segmented, covered by fine setae; basal segment $0.21 \mathrm{~mm}$ long, $0.08 \mathrm{~mm}$ wide; distal segment $0.15 \mathrm{~mm}$ long, $0.04 \mathrm{~mm}$ wide.

\section{Buccinatormyia soplaensis Arillo, Peñalver \& Pérez-de la Fuente, sp.n. \\ http://zoobank.org/urn:lsid:zoobank.org:act:C7BDF2D4-F83E- 4BC4-AAC0-F7562F656A4A \\ (Figs 3, 4, 8, 9)}

Type material. Holotype in two fragments CES-015.2 and CES-392.2, from El Soplao amber (Spain). Specimen preserved as a complete wing with a small portion of the thoracic cuticle (CES-015.2) and distal parts of the antennae and proboscis including traces of the eyes (CES-392.2).

Syninclusions. The holotype of the new species and the holotype and paratype of B. magnifica sp.n. were preserved in one large piece of amber, which was divided into several pieces to allow study of the 48 arthropods in it, including ten additional dipterans, mainly small brachycerans.

Etymology. Named after El Soplao, the amber locality where the holotype was found.
Diagnosis. Proboscis elongate (about $0.30 \times$ the body length, estimated); antenna flagellate and elongate (about $0.60 \times$ the wing length), flagellomere II with dorsal surface straight, flagellomere III about $0.65 \times$ the antennal length; Sc ending beyond level of $\mathrm{r}-\mathrm{m}$ crossvein, cell $\mathrm{m}_{3}$ broad $(\mathrm{W} / \mathrm{L}=0.34), \mathrm{M}_{2}$ and $\mathrm{M}_{3}$ highly divergent, $\mathrm{CuP}$ weakly developed.

Description (sex unknown). Body about $14 \mathrm{~mm}$ long (estimate based on comparison of wing lengths between this species and B. magnifica).

Head: Incomplete (only a portion of eye preserved as an impression, showing that eyes are large in this species, though insufficiently preserved to determine if holoptic or dichoptic).

Proboscis: Incomplete, preserved portion $1.07 \mathrm{~mm}$ long (proximal end obliquely sectioned by surface of the preparation, estimated to have originally been similar or slightly greater in length than that of B.magnifica). Proboscis laterally flattened, $0.22 \mathrm{~mm}$ high, directed forward in relation to head. Proboscis covered by dense microtrichia and a dense vestiture of large, stout setae with deep longitudinal ribbing (stellate in transverse section) and directed forward. Haustellum externally composed by a tube-like structure with a dorsal groove (=theca), subellipsoidal in cross-section and with straight lateral sides. Labrum narrow, $0.06 \mathrm{~mm}$ wide, with thickened margins (visible by cuticular transparency in a dorsal, slightly oblique position and also as an oblique section created by the surface of the amber preparation). Food canal not visible. Labellum very small, narrower than proboscis (preserved in fine detail, located very close to preparation surface, thus observable under high magnification). Labellar lobes cushion-like, $0.26 \mathrm{~mm}$ long, $c .0 .16 \mathrm{~mm}$ wide, $c$. $0.08 \mathrm{~mm}$ high; each lobe has $10-12$ pseudotracheae with $30-40$ transverse pseudotracheal rings (one labellar lobe well exposed, slightly oblique; other in perpendicular position, obscured to observation). Labellar lobes with sparse, strong setae irregularly distributed, as figured.

Antenna: Six-articled (flagellum with four flagellomeres), very elongate and flagellate, projecting forward, with same configuration as in B. magnifica sp.n. but with two flagellomeres elongated (c. $2 \times$ for flagellomere II and $c .7 \times$ for flagellomere III). Scapes not preserved, only apices of pedicels preserved; scape + pedicel of same length as in B. magnifica (inferred by the close position of the eye remains); antenna $5.62 \mathrm{~mm}$ long (estimated from reconstruction). Preserved portion of pedicel covered by long setae projecting forward. Flagellum covered by vestiture of dense, fine setulae. Flagellum long, laterally flattened, comprising four articles: flagellomere I $0.34 \mathrm{~mm}$ long, $0.03 \mathrm{~mm}$ wide, $0.12 \mathrm{~mm}$ high; II $1.18 \mathrm{~mm}$ long, $0.03 \mathrm{~mm}$ wide, $0.17 \mathrm{~mm}$ high (greatest height); III $3.03 \times$ the length of flagellomere II but with similar morphology, $3.57 \mathrm{~mm}$ long, $0.02 \mathrm{~mm}$ wide, $0.10 \mathrm{~mm}$ high basally, $0.04 \mathrm{~mm}$ high distally, $0.64 \times$ the antennal length; IV short, $0.19 \mathrm{~mm}$ long, $0.02 \mathrm{~mm}$ wide, $0.04 \mathrm{~mm}$ high. Flagellomere II with dorsal surface straight. Flagellomere III with abundant, fine, subcircular foveae (probably sensilla) c. $12 \mu \mathrm{m}$ wide (greatest width), identical to those on same flagellomere in B. magnifica, occurring 
A

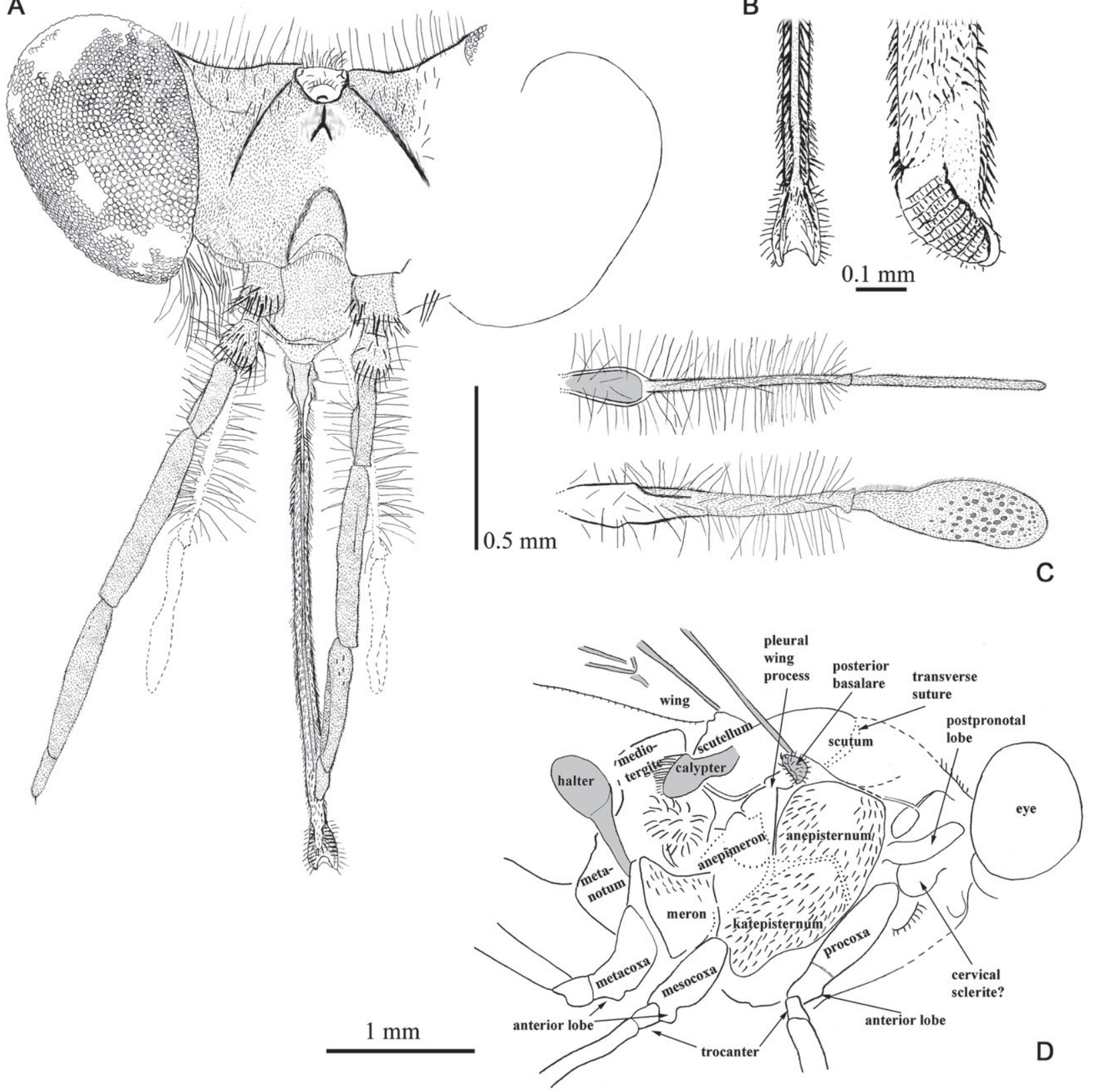

Fig. 5. Anatomical features of the holotype (CES-349.1) of Buccinatormyia magnifica gen. et sp.n. from El Soplao amber. (A) Head in dorsal view as preserved; (B) reconstructed labellum in dorsal (left) and lateral (right) views; (C) reconstructed palp in dorsal (top) and lateral (bottom) views; (D) thorax in lateral view.

on the proximal third but without apparent pattern; this flagellomere with a narrow ventrolateral band comprising dense, abundant, minute, elongate foveae ( $7 \mu \mathrm{m}$ long) (also probably sensilla, but about half the size of other foveae). Flagellomeres II and III broadly articulated with proximal article, especially flagellomere II, indicating significant lateral mobility. Flagellomeres III and IV acuminate distally, but III only on ventral margin. Minute apical stylus present, slightly longer than in B. magnifica.
Thorax: Only a small portion of the dorsal cuticle is preserved, having long setae (such setae absent in B. magnifica).

Wing: Incomplete [small basal portion and part of anal lobe not preserved (cell cup incomplete)]. Length $9.07 \mathrm{~mm}, 3.10 \mathrm{~mm}$ wide (estimated greatest width) $(\mathrm{W} / \mathrm{L}=0.34)$. Costal vein ending between $R_{5}$ and $M_{1}$. Veins $S c$ and $R$ fused basal to crossvein $\mathrm{h}$; Sc $4.46 \mathrm{~mm}$ long $(0.49 \times$ the wing length). Vein Sc meets wing margin beyond middle of wing length, beyond level of $\mathrm{r}-\mathrm{m}$ crossvein. Vein $\mathrm{R}_{1} 5.26 \mathrm{~mm}$ long; stem of Rs relatively 


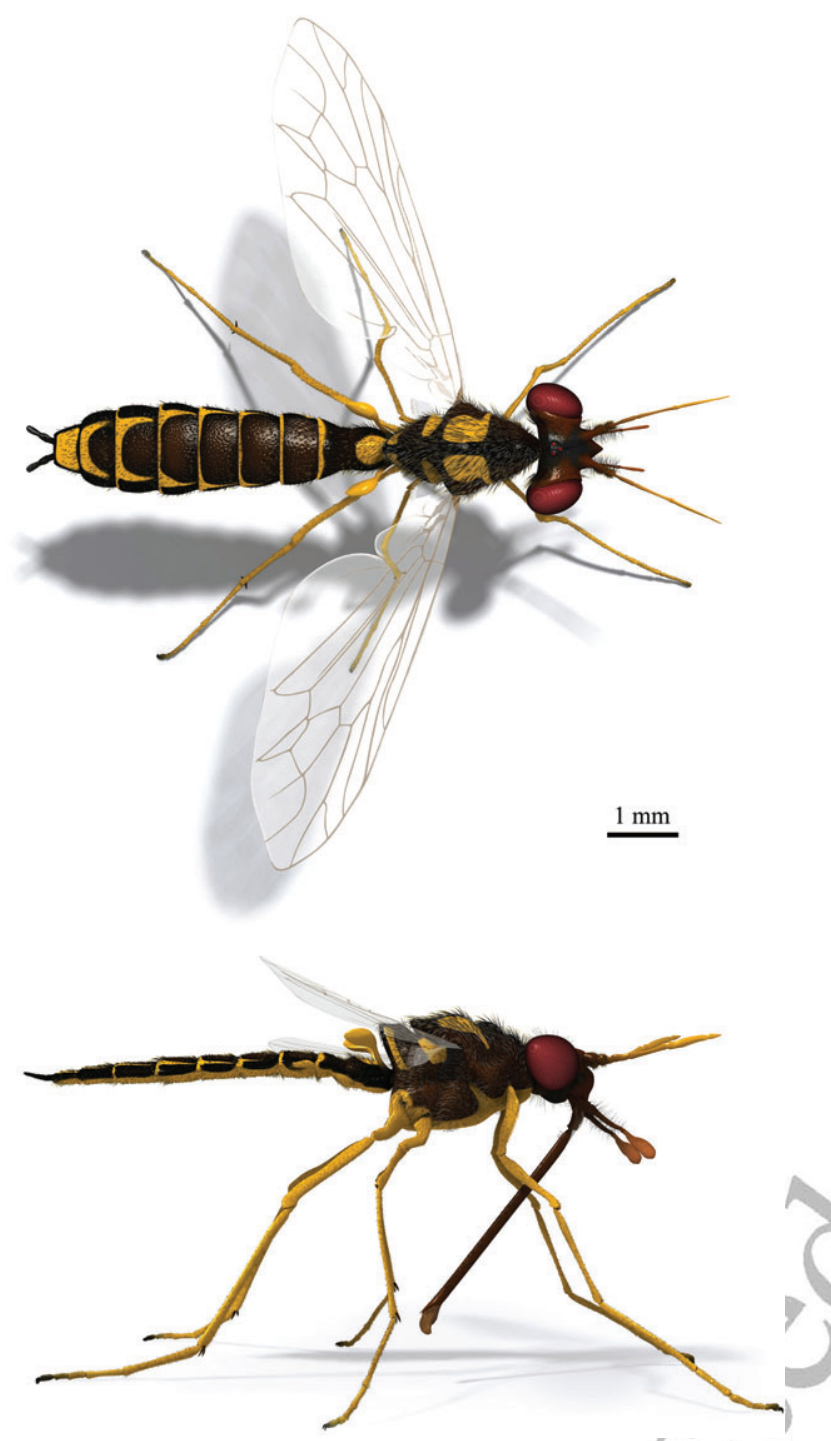

Fig. 6. Reconstruction of Buccinatormyia magnifica gen. et sp.n. in dorsal and lateral views to show its life aspect based on the holotype and paratype. The colour patterning is conjectural but based on the common black-and-yellow patterns found in Xylomyidae and Stratiomyidae (Artist: J. A. Peñas).

long, $1.55 \mathrm{~mm}$ long (c. $5.5 \times$ the length of $\mathrm{r}-\mathrm{m}$ crossvein); $\mathrm{R}_{2+3}$ $2.85 \mathrm{~mm}$ long; stem of $\mathrm{R}_{4+5} 2.33 \mathrm{~mm}$ long, $\mathrm{R}_{4}$ and $\mathrm{R}_{5}$ short but relatively longer in comparison to $B$. magnifica, asymmetrical, $\mathrm{R}_{4} 1.19 \mathrm{~mm}$ long, $\mathrm{R}_{5} 1.55 \mathrm{~mm}$ long; tip of $\mathrm{R}_{5}$ preapical to wing tip. Wing tip less acute than in B.magnifica. Cell d short and thick, $1.50 \mathrm{~mm}$ long (greatest length), $0.70 \mathrm{~mm}$ wide $(\mathrm{W} / \mathrm{L}=0.47)$. Stém of $\mathrm{M}_{1+2} 1.17 \mathrm{~mm}$ long; $\mathrm{M}_{1}$ arched costad, tip of $\mathrm{M}_{1}$ ending posterior to wing tip; $\mathrm{M}_{1} 2.02 \mathrm{~mm}$ long (linear, not along curvature), $\mathrm{M}_{2} 1.42 \mathrm{~mm}$ long; $\mathrm{M}_{1}$ and $\mathrm{M}_{2}$ virtually diverge directly from cell $\mathrm{d}$, not from a portion of $\mathrm{M}_{1+2}$ distad to cell d; veins $M_{2}$ and $M_{3}$ highly divergent. Vein $M_{2}$ ends before wing margin. Cell $\mathrm{m}_{3}$ long and broad (small distal portion lost), $1.66 \mathrm{~mm}$ long (estimated), $0.57 \mathrm{~mm}$ wide $(\mathrm{W} / \mathrm{L}=0.34)$; veins $\mathrm{CuA}_{1}+\mathrm{M}_{3}$ and $\mathrm{CuA}_{2}+\mathrm{A}_{1}$ not preserved. Cell br narrower than bm; cell bm slightly longer, $4.20 \mathrm{~mm}$ long (estimated) vs. $4.04 \mathrm{~mm}$ and distally broader due to vein $\mathrm{M}$ arched costad. Vein $\mathrm{CuA}$ with base approximately half the thickness of base of R; CuP weakly developed, not sclerotized, parallel to $\mathrm{CuA}$ and separated by distance equal to vein thickness. Veins $\mathrm{A}_{1}$ and $\mathrm{A}_{2}$ not preserved. Alula and calypter not preserved. Wing membrane entirely hyaline (no patterning or pterostigmatic sclerotization), evenly covered with minute microtrichia. Halters not preserved.

Linguatormyia Grimaldi, gen.n.

http://zoobank.org/urn:1sid:zoobank.org:act:B279141E-92044B56-9504-16E7F43D7663

\section{Type species. Linguatormyia teletacta gen. et sp.n.}

Etymology. Derived from lingua- (L.), tongue, and -myia (Gr.), fly, in reference to the long proboscis.

Diagnosis. Antenna with five articles (three flagellomeres), without minute apical stylus; stem of Rs short (shorter than r-m crossvein), $M_{1}$ and $M_{2}$ diverging directly from cell $d$ (not from a portion of $\mathrm{M}_{1+2}$ distad to cell $\mathrm{d}$ ), vein $\mathrm{A}_{2}$ absent.

Linguatormyia teletacta Grimaldi, sp.n.

http://zoobank.org/urn:1sid:zoobank.org:act:8A386070-4F23-

45F9-A6A6-DD527B6A55BC

(Figs 10-13)

Type material. Holotype AMNH Bu-SE13, in Burmese amber (Myanmar). The specimen is in a $36 \times 30 \times 11 \mathrm{~mm}$ piece of dark, turbid amber containing fine particulate debris, transverse fractures and flow lines (especially near the centre). These obscure some features of the specimen, especially dorsally. The entire head, palp, proboscis and even antennae are preserved, as is the thorax and most of the abdomen (except for its tip). Lost at the surface of the amber are tip of the right wing and apices of all tibiae and all tarsi. Distal third of right wing is folded $3 \times$ and required careful reconstruction.

Syninclusions. Two thrips (Thysanoptera), a small beetle, an empidoid fly, a portion of a neuropteran wing, and insect frass.

Etymology. Combination of tele (G.), far, and tactus (L.), sense of touch, meaning 'far touching', in reference to the strikingly elongate antennae.

Diagnosis. As for genus, with the following additions: proboscis very long (about $0.45 \times$ the body length); antenna flagellate and extremely elongate (about $1.80 \times$ the wing length), flagellomere III about $0.80 \times$ the entire antennal length. 

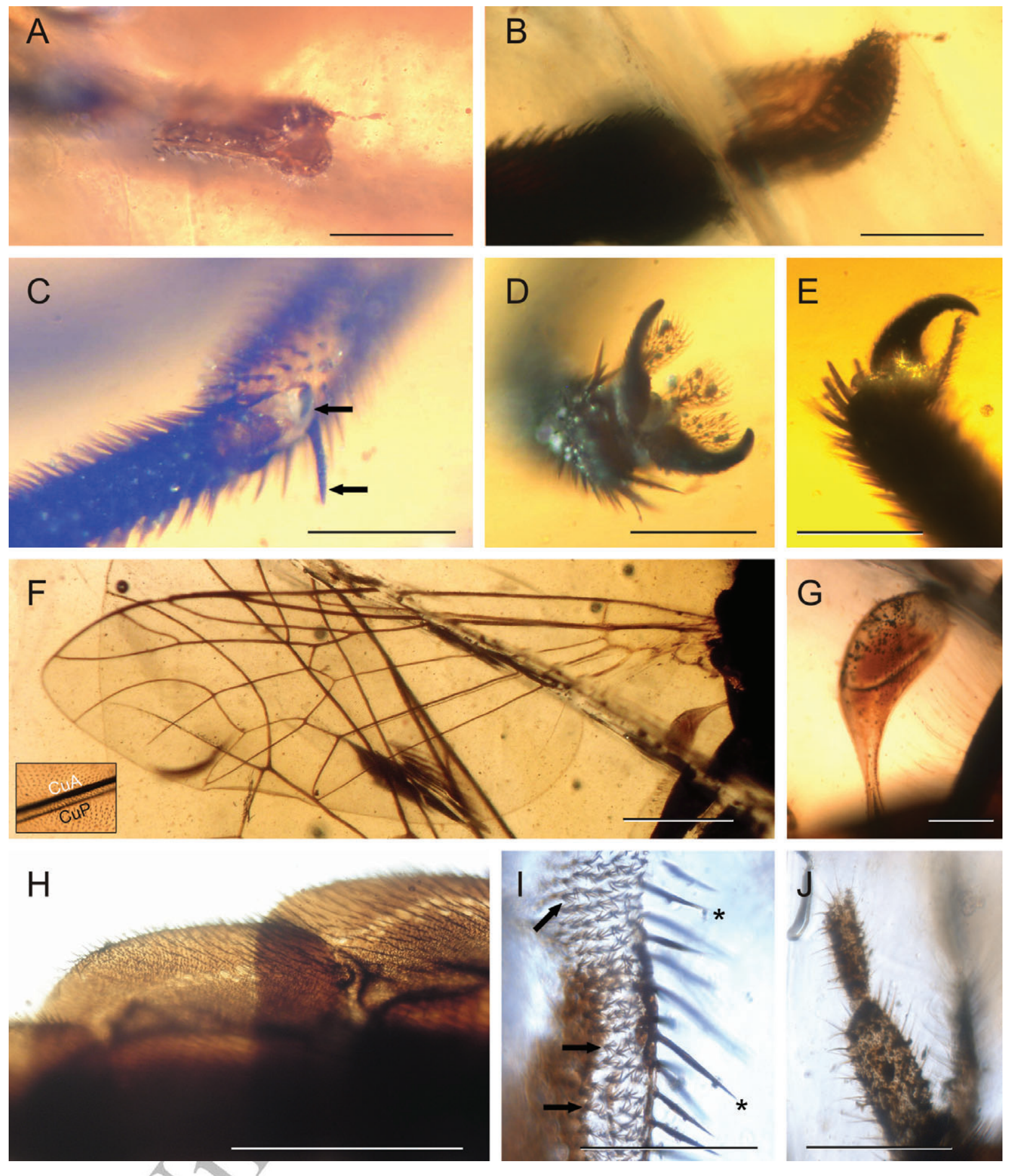

Fig. 7. Anatomical features of the holotype of Buccinatormyia magnifica gen. et sp.n. from El Soplao amber (CES-349.1), except subfigures (F and G) from the paratype (CES-015.1/CES-392.3). (A, B) Labellum in dorsolateral and lateral views showing labellar lobes with fine pseudotracheae; (C) metatibia showing the intersegmental membrane with two tibial spurs (arrows); (D) metatarsus showing paddle-shaped pulvilli, empodium and claws covered by microtrichia; (E) pretarsus in lateral view; (F) wing (inset: sclerotized CuP); (G) halter in dorsal view; (H) two of the major abdominal 'lateral flanges' with series of abdominal muscle plaques; (I) margin of an abdominal 'lateral flange' showing dense vestiture of 'stellate hairs' (arrows), constituted by microtrichia arranged in bunches and large, stiff deeply-ribbed setae (stellate in transverse section) similar to those on proboscis (asterisks); (J) female terminalia with two-segmented cerci. Subfigures (C, D) and (I, J) made with consecutive pictures taken at successive focal planes. Scale bars: (A-C, G, J) $0.2 \mathrm{~mm}$; (D, E, I) $0.1 \mathrm{~mm}$; (F) $1.0 \mathrm{~mm}$; (H) $0.5 \mathrm{~mm}$. 
A
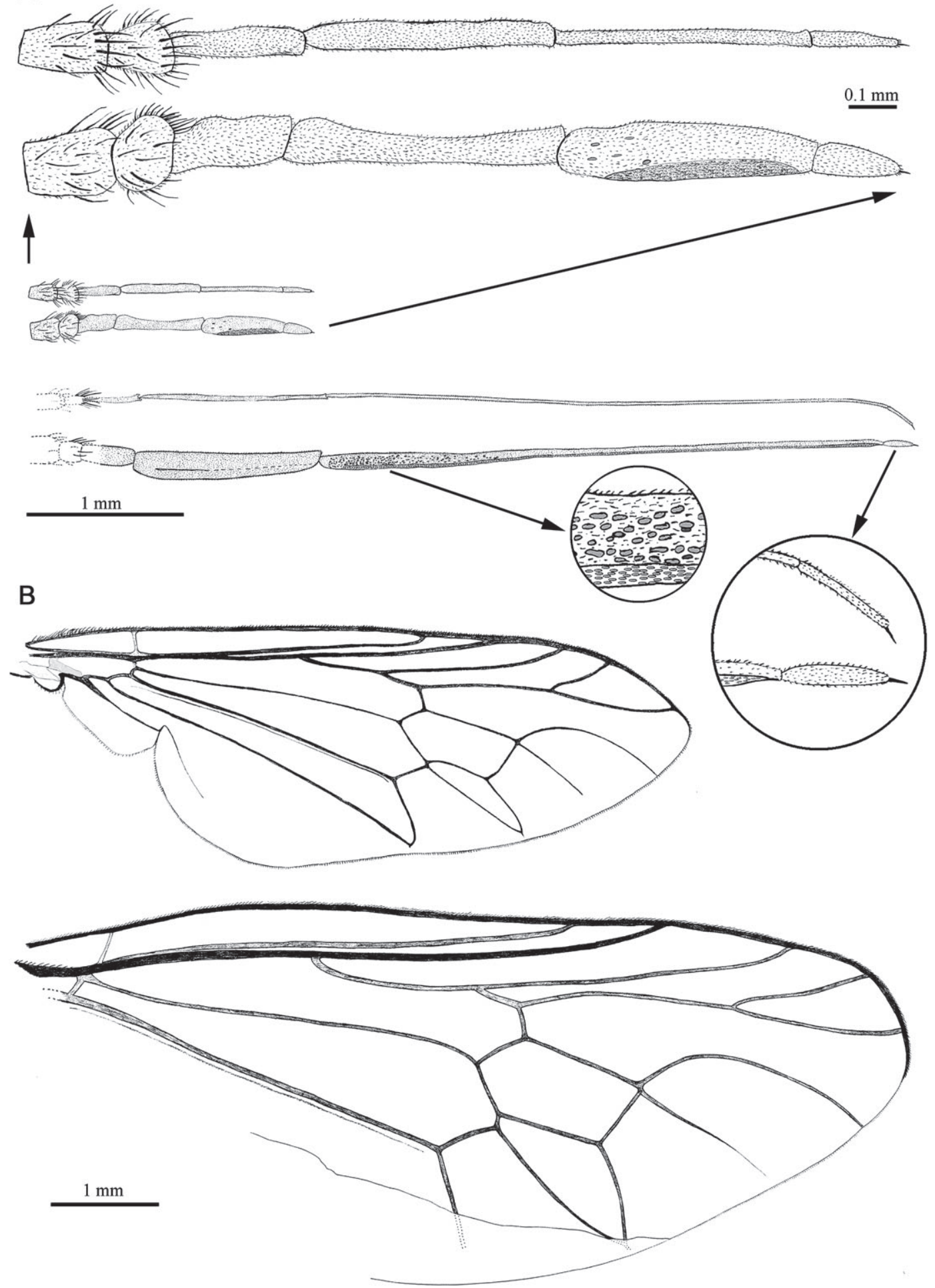

Fig. 8. Comparison between antennae (A) and wings (B) of Buccinatormyia magnifica gen. et sp.n. (top in both subfigures) and B. soplaensis sp.n. (bottom in both subfigures), drawn to the same scale. Antennae depicted in fully lateral and dorsal views. Antennal views of $B$. magnifica enlarged for relative comparison of antennal articles with those from B. soplaensis. Insets in antennal views of B. soplaensis showing fovea on flagellomere III (left inset) and minute apical stylus (right inset). Wing of B. magnifica taken from the paratype; rest of the subfigures taken from their respective holotypes.

(C) 2014 The Royal Entomological Society, Systematic Entomology, 0, 0-0 

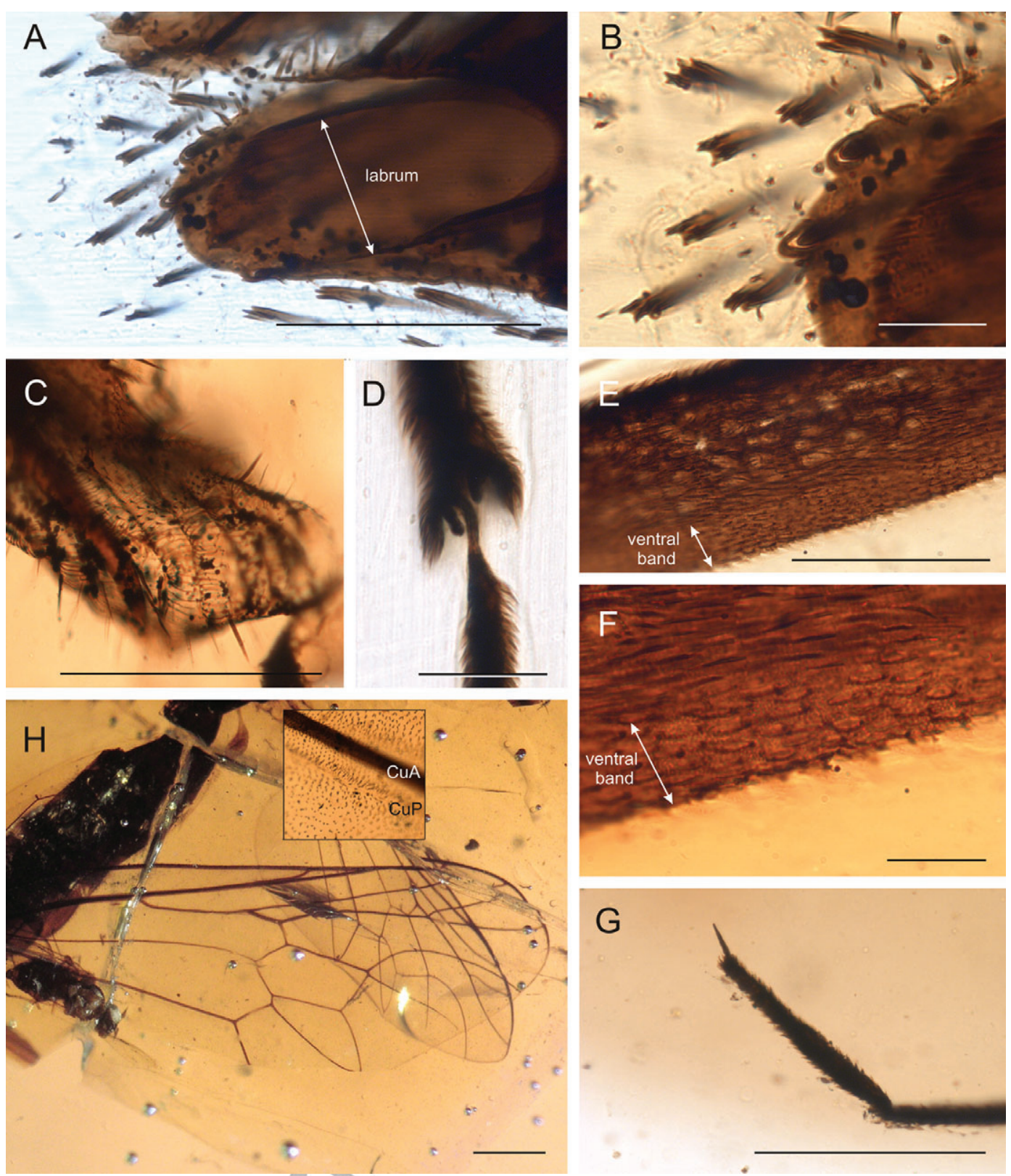

Fig. 9. Anatomical features of Buccinatormyia soplaensis sp.n. from El Soplao amber, holotype CES-015.2/CES-392.2. (A) Oblique section of the proboscis showing the labrum; (B) detail of the same section showing the large, stiff deeply-ribbed setae with stellate transverse section; (C) cushion-like labellar lobe showing abundant, fine pseudotracheae transversally crossed by abundant pseudotracheal rings; (D) broad articulation of flagellomere II; (E) detail of the two groups of fine foveae on the proximal third of flagellomere III; (F) detail of the narrow ventral band of small foveae on the same flagellomere; $(\mathrm{G})$ flagellomere IV with minute apical stylus; $(\mathrm{H})$ wing (inset: weakly developed CuP). Subfigures $(\mathrm{C}, \mathrm{E}$ and F) made with consecutive pictures taken at successive focal planes. Scale bars: (A, E) $0.1 \mathrm{~mm}$; (B, F) $0.02 \mathrm{~mm}$; (C, G) $0.2 \mathrm{~mm}$; (D) $0.05 \mathrm{~mm}$; (H) $1.00 \mathrm{~mm}$.

Description (sex unknown). Bódy $8.92 \mathrm{~mm}$ long.

Head: Broad, $2.67 \mathrm{~mm}$ wide. Eyes large, occupying nearly entire lateral surface of head (genae exposed ventrally), widely separated (ventrally $1.22 \mathrm{~mm}$ between inner margins); bare, devoid of interfacetal setulae; facets undifferentiated; inner margins in frontal view with slight emarginations around antennal base (depth of emargination approx. half the diameter of antennal socket). Anterior ocellus apparently present, small; posterior ocelli either minute or lost. Vertex of head with paramedian emarginations, centrally raised into bare, median dorsal tubercle; vertex with short, stiff setulae. Areas surrounding antennal bases raised into bare, rounded mounds (=facial lobes), nearly meeting medially. Front of head with well-developed, inverted Y-shaped sulcus; diverging arms separating clypeus and 


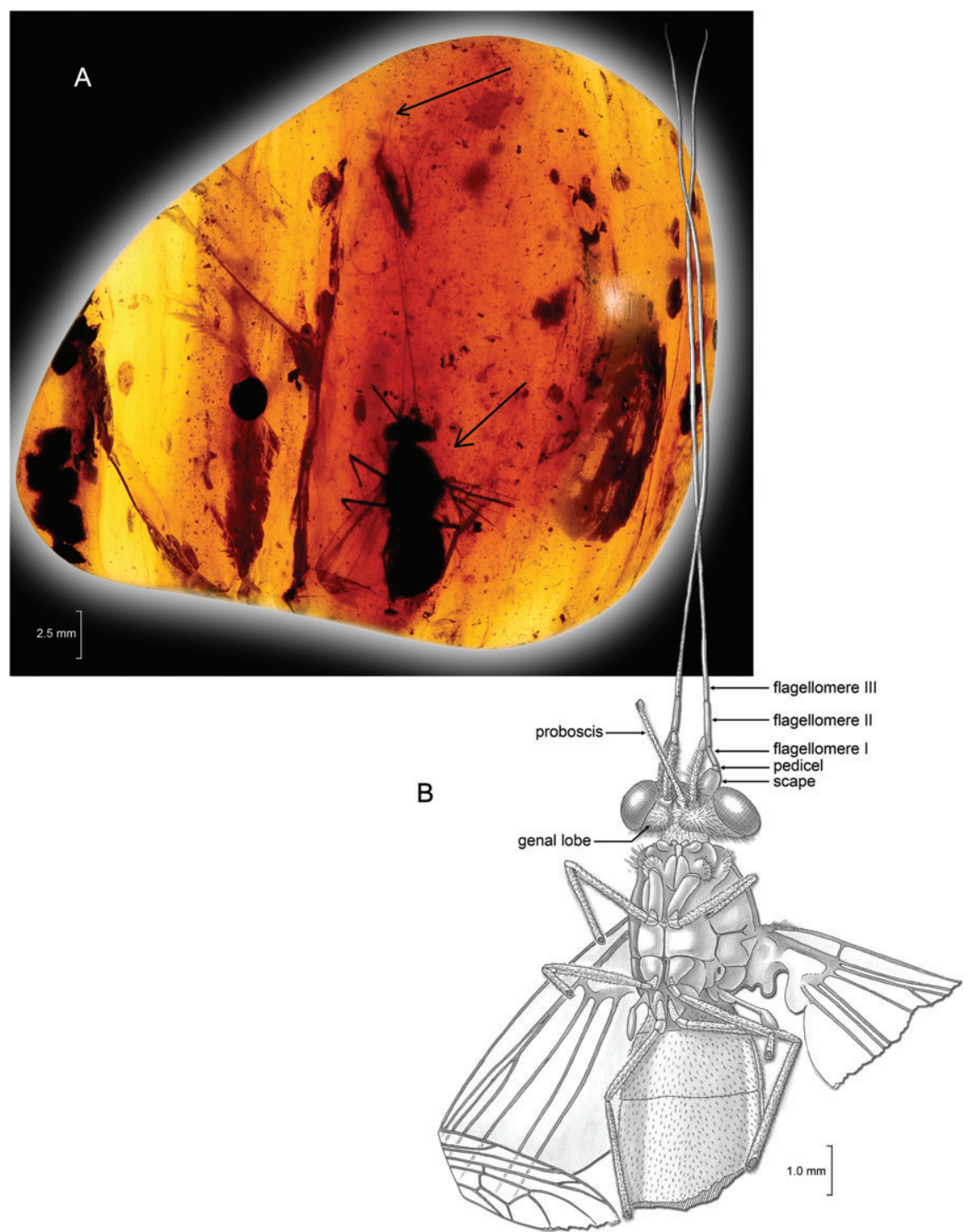

Fig. 10. Linguatormyia teletacta gen. et sp.n. in Burmese amber, holotype AMNH Bu-SE13. (A) Photomicrograph of amber piece containing the specimen. Arrows indicate body of fly (bottom) and tips of antennae (top); (B) Drawing of entire holotype (ventral view), shown as preserved.

ventral margins of facial lobes, these arms meet frontogenal sulci beneath antennal sockets; straight arm running between pair of facial lobes up frons to anterior ocellus. Clypeus bare, raised into low mound between facial lobes and palpal bases, fully frontal in position; with short vertical, median suture; ventral surface of clypeus membranous, oval, membrane connected to base of proboscis, with dorsomedial ligament. Frontoclypeal sulci (demarcating tateral edges of clypeus) very deep, exposing pair of anterior tentorial pits. Genae developed into pair of rounded, ventral lobes; lobes slightly separated beneath base of proboscis (not touching); with dense, fine setulae. Neck entirely membranous, $0.80 \mathrm{~mm}$ thick.

Proboscis: Long (virtually all of it haustellum), $4.37 \mathrm{~mm}$ long (measured from CT scan), $0.46 \times$ the body length. Proboscis laterally flattened (width $0.43 \times$ the cross-sectional depth); barely tapered in width or depth apicad; covered with dense, thick microtrichia for entire length. Base of proboscis ventrally with annulated membrane (ventral rostral membrane), ten annulations exposed (membrane probably telescoped). Dorsal portion of proboscis semi-tubular (labrum probably forming dorsal wall, epi/hypopharynx not visible, but most likely forming floor), surrounding hollow food canal; smaller ventral portion solid (probably a distended labium and/or prementum). Labellum very small, as wide as proboscis, depth slightly greater than width; length slightly less than depth; labellar lobes closely pressed together medially, with fine pseudotracheae on exposed surfaces.

Maxillary palp: Elongate, $1.47 \mathrm{~mm}$ long, projected forward, two-segmented. Bases of palps flank base of proboscis (as preserved, apical palpomeres virtually in contact with 

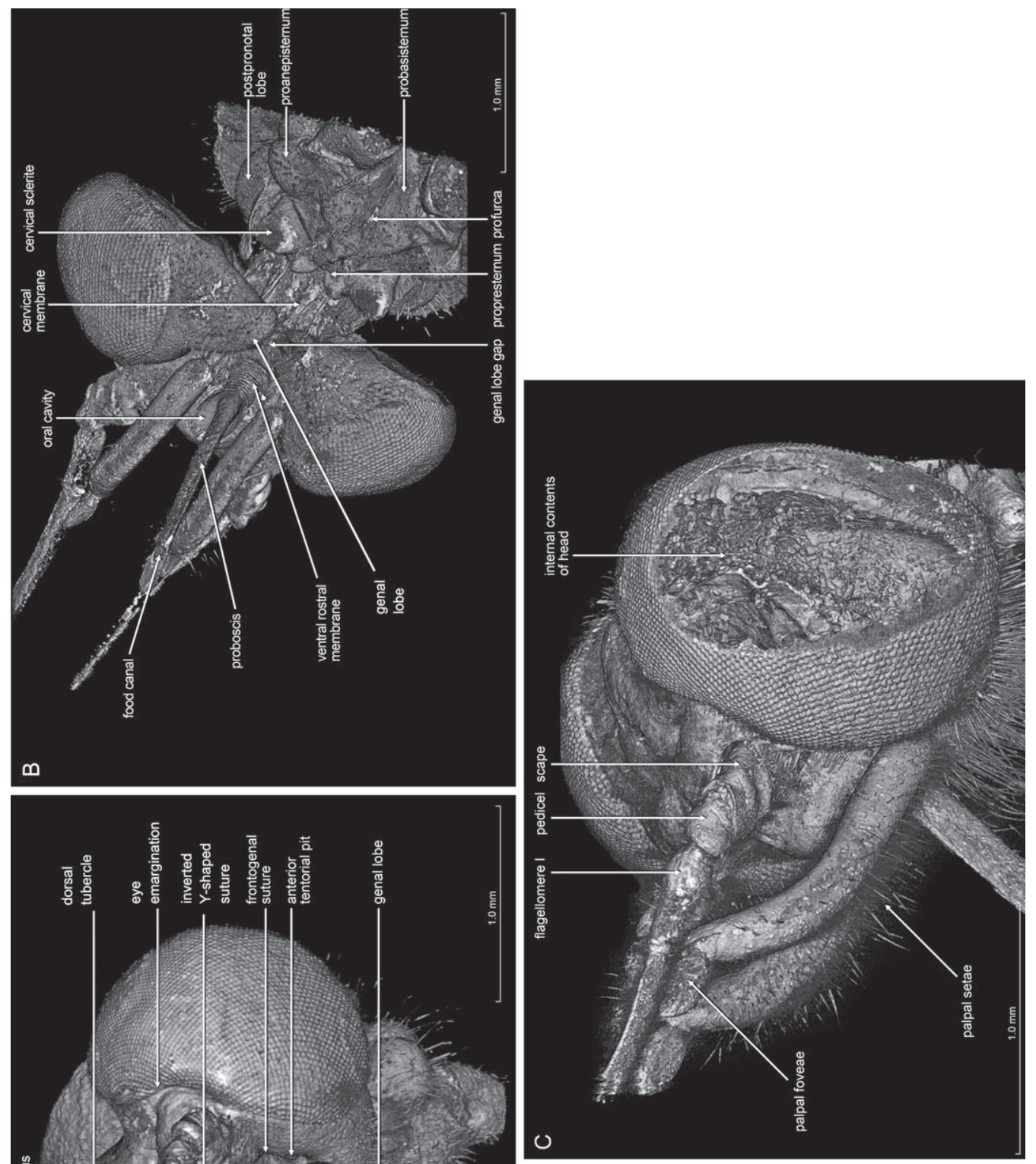

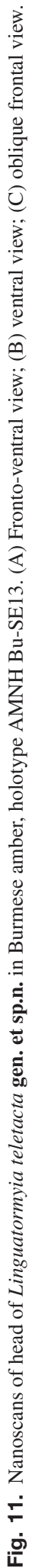

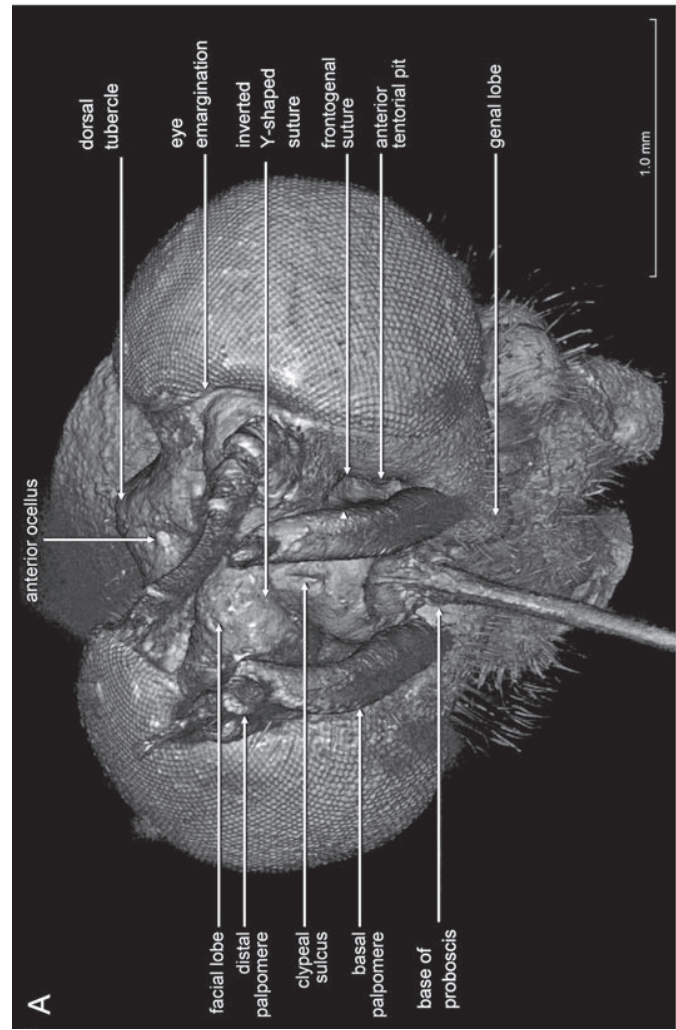




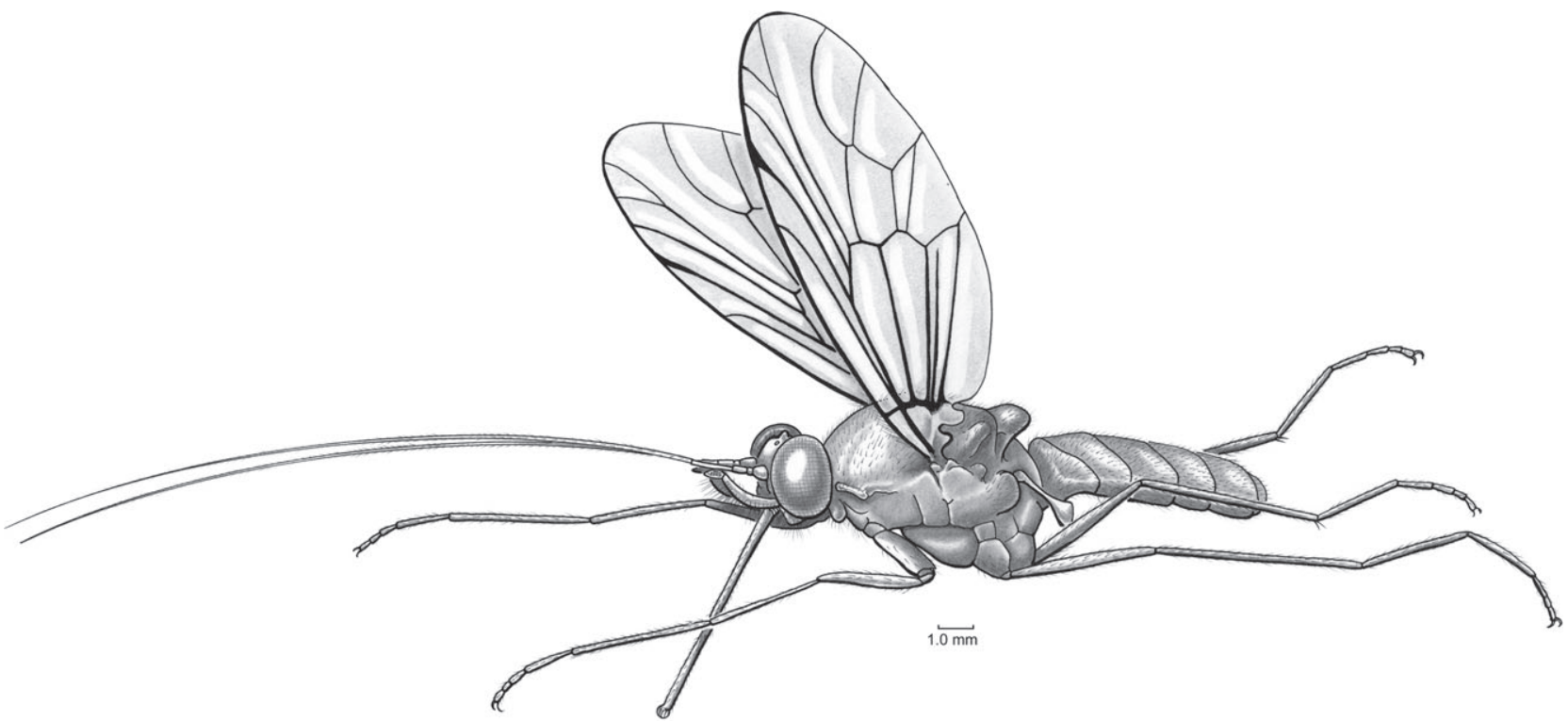

Fig. 12. Reconstructed habitus of Linguatormyia teletacta gen. et sp.n. in Burmese amber.

antennae). Basal palpomere long, $0.80 \times$ the total palp length; tubular, $0.20 \mathrm{~mm}$ wide; curved gently upward; ventral half covered with fine, stiff setae; with very fine transverse suture (appears under transmitted visible light; this suture is not visible in CT scans, indicating it may be only internally developed). Apical palpomere short, oval, not pedunculate, laterally flattened, pointed anteriad, bare; lateral surface with three longitudinal rows of fine foveae (probably sensilla).

Antenna: Five-articled (with three flagellomeres), projecting forward, extremely elongate and flagellate; $15.40 \mathrm{~mm}$ long (1.62 $\times$ estimated body length) (as preserved antennae converge and cross twice, at $0.5 \times$ and $0.65 \times$ their total length). Antennal bases broadly separated by distance $3 \times$ diameter of antennal socket $(1.75 \times$ distance between palp bases), lying within shallow emarginations of inner margin of eyes. Scape short, slightly wider than long; as preserved both scapes are oriented anterolaterally (divergent). Pedicel short, $0.37 \times$ length of scape, $0.48 \times$ the width [pedicels and flagellomeres I pointed mesally (convergent)]. Flagellum extremely long, slender, tapered, laterally flattened; with dense, fine setulae. Flagellum comprising three flagellomeres: I as long as scape, $0.40 \mathrm{~mm}$ long, $0.16 \mathrm{~mm}$ wide; II $0.97 \mathrm{~mm}$ long, $0.13 \mathrm{~mm}$ wide; III $12.8 \mathrm{~mm}$ long, $0.83 \times$ the antennal length. Minute apical stylus absent.

Thorax: Broad and deep, $2.68 \mathrm{~mm}$ wide, slightly wider than head; devoid of macrosetae, exocuticle with fine, short, pile-like setae only; coloration appears uniformly dark brownish (possibly preservational). Prothorax highly reduced, as in other Diptera, but with some modifications. Propresternum a small central, anterior sclerite with pair of small lobes protruding anteriorly (lobe diameter $0.12 \mathrm{~mm}$ ). Flanking these lobes is pair of hemispherical, protruding lobes, diameter $0.25 \mathrm{~mm}$ (=cervical sclerites) shifted ventrally from lateral positions typical of most flies; cervical sclerite extremely heavily sclerotized (based on density in CT scans), with covering of sparse setulae.
Immediately posterior to propresternum is probasisternum, $c$. $3-4 \times$ the size of former sclerite, with sulcus demarcating profurca well defined. Lateral and dorsal to cervical sclerites is a pair of flattened, triangular postpronotal lobes with short pilosity. Between these lobes and probasisternum is small, triangular sclerite with bulging lobe, i.e. proanepisternum. Base of proanepisternum articulating with base of procoxa. Mesothorax large, expansive. Katepisternum ventrally broad and slightly bulging, with median sulcus of furca well defined. Anepisternum very large; anepimeron smaller, subdivided by partial cleft; katatergite rounded, bulging, setulose; mesothoracic spiracle immediately ventral to katatergite; meron slightly larger than mesocoxa. Coxae and ventral surfaces of femora with sparse, short setulae. Procoxae slender, $1.01 \mathrm{~mm}$ long, well separated from each other; mesocoxae closer together, bases nearly contiguous, $0.58 \mathrm{~mm}$ long, $0.51 \mathrm{~mm}$ wide basally; metacoxal bases contiguous, $0.45 \mathrm{~mm}$ long, anterior surface of metacoxa with a small, protruding lobe. Trochanters small, slender, fully articulated with femora and coxae (no fusion). Femora slender, profemur $2.14 \mathrm{~mm}$ long, mesofemur $2.12 \mathrm{~mm}$ long, metafemur $2.89 \mathrm{~mm}$ long; each dorsally with dense, recumbent setulae. Tibiae slender (none with apex preserved), entirely covered with dense setulae.

Wing: Length $8.64 \mathrm{~mm}$ (from reconstruction); $3.39 \mathrm{~mm}$ wide (greatest width) $(\mathrm{W} / \mathrm{L}=0.39)$. Vein $\mathrm{C}$ not circumambient (wing tip lost). Veins Sc and R fused basal to crossvein h; Sc $3.71 \mathrm{~mm}$ long $(0.36 \times$ the wing length), Sc ending beyond level of $r-m$ crossvein. Vein $\mathrm{R}_{1} 4.82 \mathrm{~mm}$ long, gradually thickened apically; stem of Rs short, $0.50 \mathrm{~mm}$ long; $\mathrm{R}_{2+3} 3.64 \mathrm{~mm}$ long; stem of $\mathrm{R}_{4+5} 3.43 \mathrm{~mm}$ long, $\mathrm{R}_{4}$ and $\mathrm{R}_{5}$ short, asymmetrical, $\mathrm{R}_{4}$ $0.93 \mathrm{~mm}$ long, $R_{5} 1.34 \mathrm{~mm}$ long, tip of $R_{5}$ preapical to wing tip. Cell d short and thick, $1.50 \mathrm{~mm}$ greatest length, $0.68 \mathrm{~mm}$ wide $(\mathrm{W} / \mathrm{L}=0.45)$. Stem of $\mathrm{M}_{1+2} 1.57 \mathrm{~mm}$ long; $\mathrm{M}_{1}$ arched costad, tip of $\mathrm{M}_{1}$ probably ending posterior to wing tip (based on trajectory 

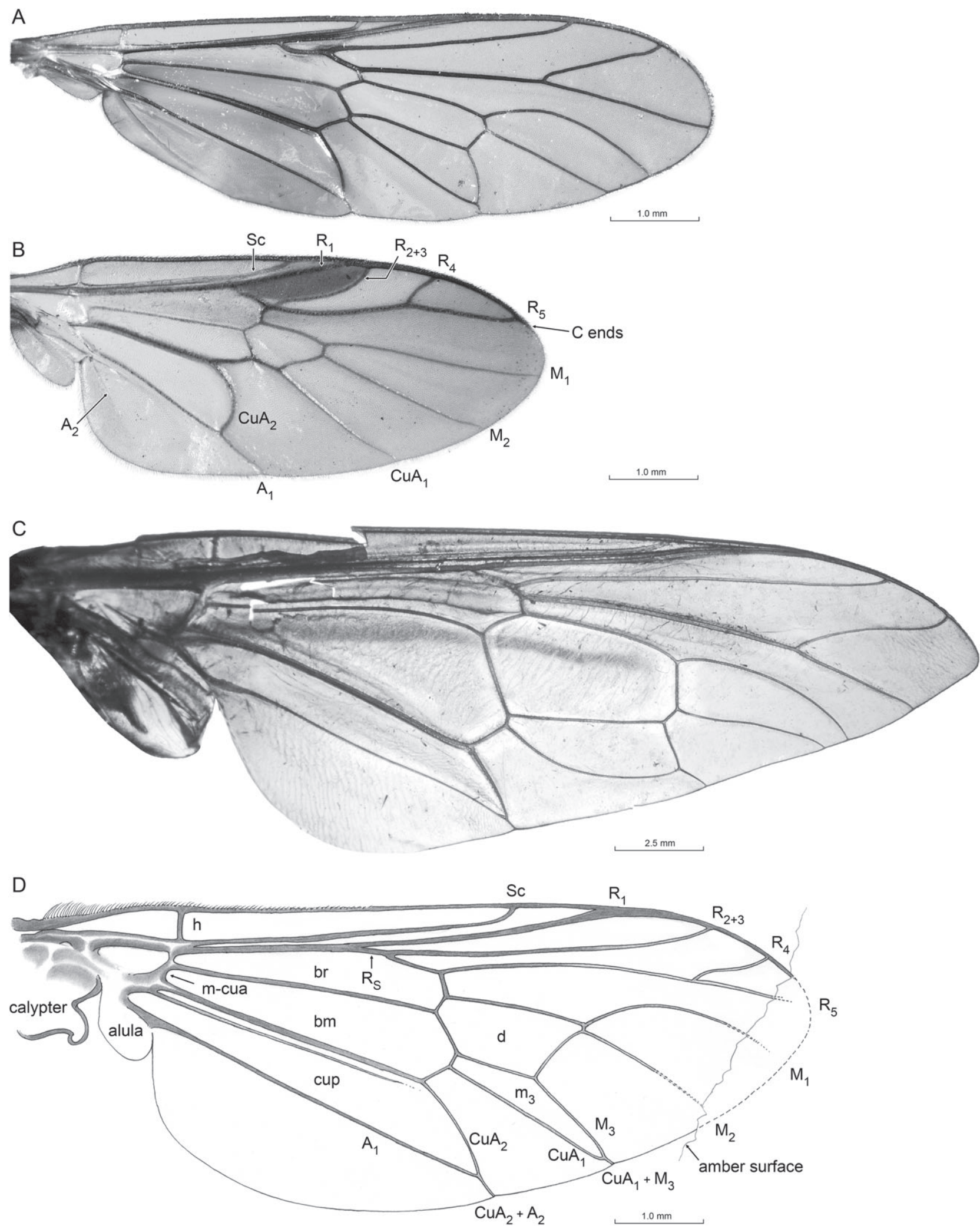

Fig. 13. Wings of recent (A-C) and fossil (D) stratiomyomorphans. (A) Xylomyia americana (Xylomyidae); (B) Allognosta fuscitarsis (Stratiomyidae); (C) Pantophthalmus sp. (Pantophthalmidae); (D) Linguatormyia teletacta gen. et sp.n. (Zhangsolvidae). 
of vein), $M_{1} 2.25 \mathrm{~mm}$ long (linear, not along curvature); $\mathrm{M}_{2}$ $1.86 \mathrm{~mm}$ long; $\mathrm{M}_{1}$ and $\mathrm{M}_{2}$ diverge directly from cell $\mathrm{d}$, not from a portion of $M_{1+2}$ distad to cell $d$; veins $M_{2}$ and $M_{3}$ nearly parallel. Apices of veins $\mathrm{R}_{4}, \mathrm{R}_{5}, \mathrm{M}_{1}$ and $\mathrm{M}_{2}$ very thin, faint. Cell $\mathrm{m}_{3}$ long and slender, $1.96 \mathrm{~mm}$ long, $0.39 \mathrm{~mm}$ wide $(\mathrm{W} / \mathrm{L}=0.20)$; veins $\mathrm{CuA}_{1}$ and $\mathrm{M}_{3}$ joined in very short vein before meeting wing margin. Cell br slightly narrower than bm; cell bm slightly longer (3.35 mm long vs. 3.00). Vein $\mathrm{CuA}$ with base very thick, approximately same thickness as base of R; $\mathrm{CuA}_{2}$ fusing with $\mathrm{A}_{1}$ prior to wing margin, forming closed, narrow cell cup; cup $4.42 \mathrm{~mm}$ long (W/L=0.16); $\mathrm{CuP}$ well developed, parallel to $\mathrm{CuA}$ and separated by distance equal to vein thickness. Vein $A_{1}$ entirely straight; no trace of $A_{2}$ evident. Anal lobe, alula and calypter well developed; calypter with marginal vein. Wing membrane entirely hyaline (no patterning or pterostigmatic sclerotization), evenly covered with minute microtrichia. Halter with slender apical club.

Abdomen: Broad, $3.00 \mathrm{~mm}$ wide, slightly broader than thorax, as preserved dorsoventrally flattened. Five basal sternites and five basal tergites preserved, all with dense, short setulae. Sternites cover entire transverse width of abdomen; no abdominal pleural membrane exposed. Terminalia not preserved.

Remarks. Sex of the unique specimen cannot be definitively determined without terminalia, but the dichoptic condition suggests it may actually be a female. Orthorrhaphous Brachycera commonly have holoptic males, exceptions being all Apioceridae, Asilidae, Vermileonidae and Xylomyidae, some Xylophagidae and Bombyliidae, and the genus Tongamyia (Mydidae).

Linguatormyia teletacta gen. et sp.n. differs from other zhangsolvids in wing venation (most comparable structure for all fossil species) as follows: from Buccinatormyia soplaensis sp.n. by having much more slender cell $\mathrm{m}_{3}(\mathrm{~W} / \mathrm{L}=0.20$, vs. 0.38 ), $M_{2}$ and $M_{3}$ nearly parallel (vs. highly divergent); from Cratomyia by lacking a stem of $\mathrm{M}_{1}$ and $\mathrm{M}_{2}$ and by having a broader wing $\left(\mathrm{W} / \mathrm{L}=0.39\right.$, vs. 0.35), lacking $\mathrm{A}_{2}$, and cell d broader (W/L $=0.43$, vs. 0.37 ); from Zhangsolva by the broader wing (vs. 0.34) and proximal end of cell d with two shallow, unequal sides (vs. equilateral ' $V$ '-shaped sides); and from the other four genera by the short stem of Rs, which is shorter than $\mathrm{r}-\mathrm{m}$ crossvein (vs. several times the crossvein length).

\section{Discussion}

Some important characters have not been included in the diagnoses of the new genera because they are unknown from B. soplaensis sp.n. However, these characters are remarkably different between B. magnifica gen. et sp.n. and Linguatormyia teletacta gen. et sp.n. and hence they hold a potential diagnostic significance between the two genera in which they have been classified. The most important characters of these are based on the palp morphology. In B. magnifica, the basal palpomere is long $(0.60 \times$ the total palp length), inflated basally and gradually narrowing distally (with distal $2 / 3$ strongly flattened laterally), and straight; whereas the apical palpomere is long, club-like, pedunculate and with a broad, rounded apex. In contrast, in L. teletacta the basal palpomere is very long $(0.80 \times$ the total palp length), tubular and curved gently upward, whereas the apical palpomere is short, oval, not pedunculate, and pointed anteriorly. Moreover, the dorsal width of the eyes is broader in B. magnifica (a condition apparently present as well in Cratomyia, though preservation in limestone makes this uncertain) but nearly equal to the ventral width in L.teletacta (only a small portion of the eyes is preserved in B. soplaensis).

Even though the palps, as mentioned, are not preserved in the unique specimen of B. soplaensis, and that this species shares with L. teletacta the remarkable presence of flagellate antennae - a unique feature among all extinct or extant Brachycera we are placing the former within the genus Buccinatormyia based on wing characters and antennal structure. Indeed, along with the fewer antennomeres and the absence of an apical stylus, the antenna of L.teletacta is much more elongate, nearly $2 \times$ the wing length (vs. less than the wing length in B. soplaensis) and flagellomere III comprises $0.83 \times$ the entire antennal length (vs. $0.64 \times$ in B. soplaensis). Zhangsolva possesses a basic antennal structure with multiple articles having little differentiation (probably with no more than eight flagellomeres; see comments above).

The presence of two morphotypes of a rare family, Zhangsolvidae, in the same piece of Spanish amber with similar wing venation could be interpreted as a male and female of the same species, rather than separate species as we propose. Under this hypothesis, the three specimens were captured possibly during swarming or mating. However, B. magnifica (the smaller species) is represented by a female that has the terminalia well preserved, and this size dimorphism would be unlike any seen in orthorrhaphous Brachycera. Based on our measurements of 30 exemplar genera and 34 species in the three extant families of Stratiomyomorpha, males are usually smaller than females, sometimes substantially so. The presence and degree of body size dimorphism varies to some extent based on whether the measurement is thorax or wing length, because in 18 of 26 stratiomyid species the females were larger based on thorax length, and in 21 of 26 species females were larger based on wing length (males were consistently smaller in pantophthalmids and xylomyids). For all three families the pattern of larger females is highly significant $(P \ll 0.01$, oneand two-tailed sign tests). On average, female stratiomyids were larger by $6-9 \%$ (depending on the length measurement), female pantophthalmids by $6-20 \%$, and female xylomyids by $9-16 \%$. The wing length of the female holotype of B. magnifica is $6.00 \mathrm{~mm}$ - that of B. soplaensis is $9.07 \mathrm{~mm}$ (sex unknown). Therefore, if B. soplaensis were the male of B. magnifica its $44 \%$ larger size would completely contradict the size dimorphism seen in extant stratiomyomorphans.

Sexual dimorphisms of discrete characters in extant flies can be very dramatic, commonly involving a character system such as leg ornamentation, eye stalks, or body/wing coloration. Not only is the holotype of B. soplaensis considerably larger than the known female of the genus, but it has very long, flagellate antennae and different wing venation (see diagnosis of B. soplaensis, above). Sexual dimorphism in venation is rare 

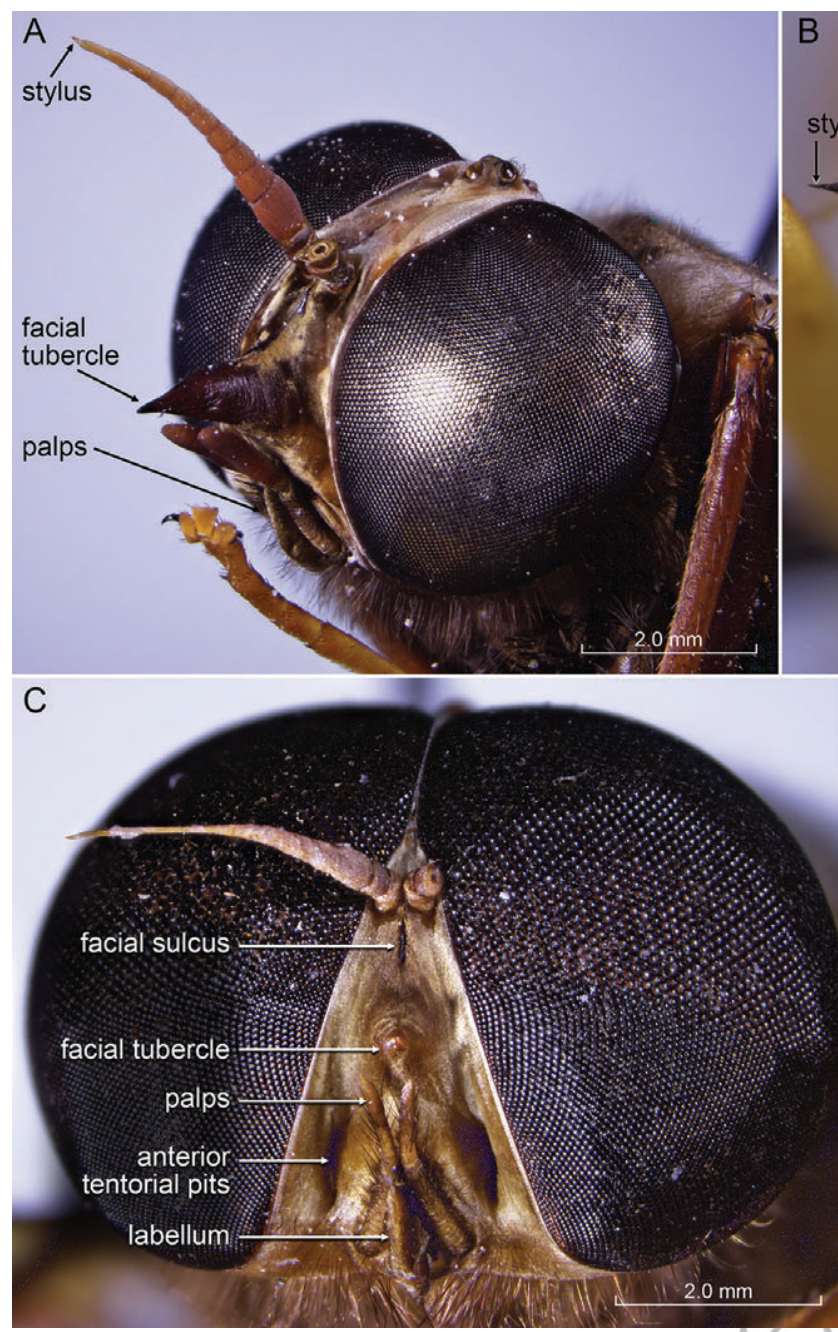

Fig. 14. Heads of recent stratiomyomorphans, showing some of the characters used in the phylogenetic analysis. (A, B) Oblique frontal views; (C, D) fronto-ventral views. (A) Pantophthalmus kerteszianus (Pantophthalmidae); (B) Xylomyia americana (Xylomyidae); (C) Pantophthalmus comptus; (D) Chiromyza sp. (Stratiomyidae).

in flies, including extant Stratiomyomorpha, and is generally subtle. Val (1976) records slight sexual differences in the venation of a few species of Pantophthalmus Thunberg, but, given the rarity of these flies, it is uncertain as to how consistent are these differences. The most obvious example involves Pantophthalmus batesi Austen, in which the size of cell $\mathrm{m}_{3}$ is slightly smaller in the male (cell width of 0.31 relative to length, vs. 0.40 in the female). In B. soplaensis, cell $\mathrm{m}_{3}$ is actually much broader $(0.38)$ than in the known female of the genus (0.22).

Dimorphism in antennal structure does occur in Stratiomyomorpha, most obvious in, again, the genus Pantophthalmus, where the female has a larger, stout flagellum (of eight flagellomeres) and the male a smaller, conical one with the apical article being styliform and $0.5-2 \times$ the length of the basal article (Fig. 14; Val, 1976). Woodley (1995) reported dimorphism in the size of antenna of about eight genera of beridine
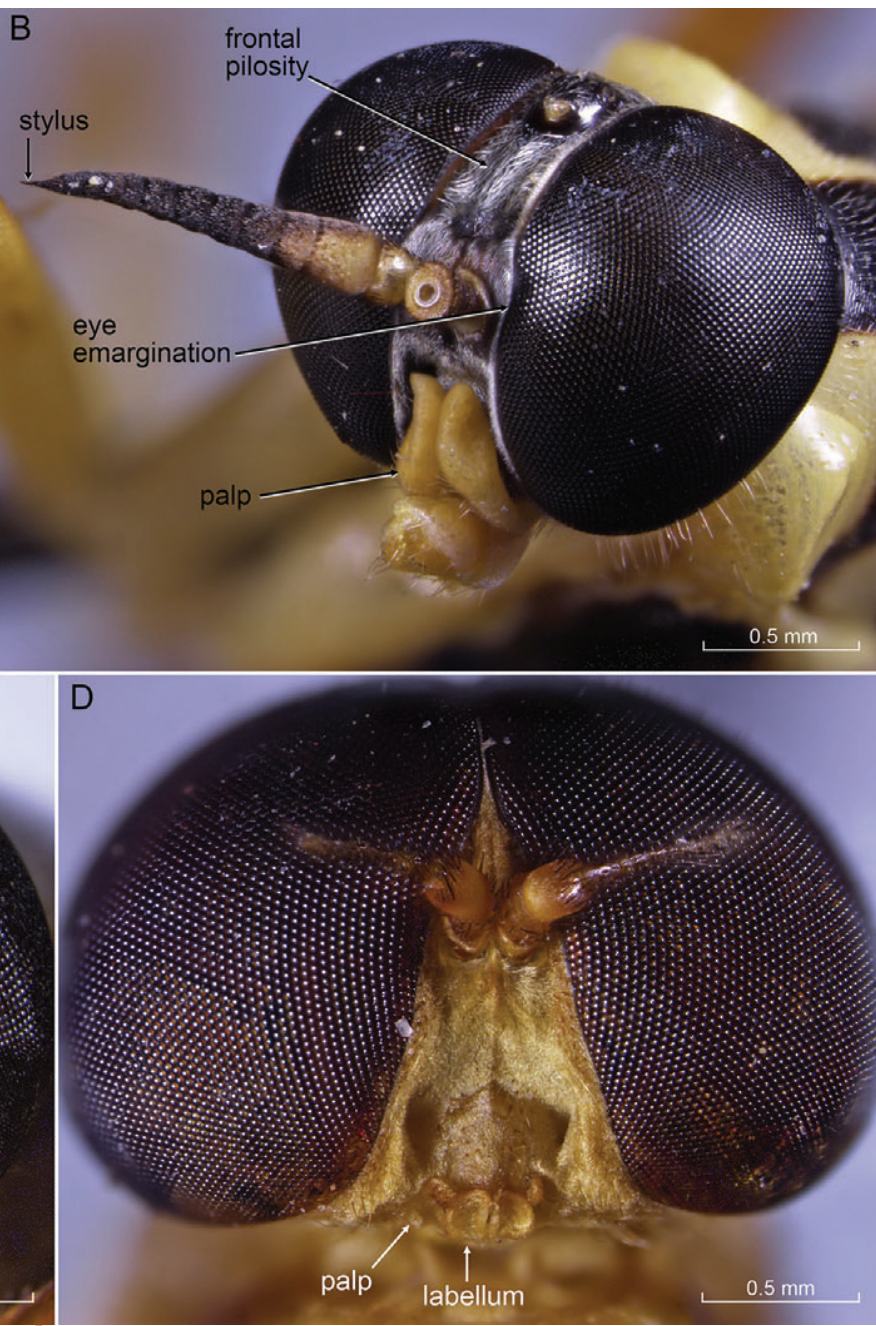

Stratiomyidae, those in males being slightly smaller. The antenna of female pantophthalmids is actually larger than in males, so in both these groups the sexual differences are opposite what would be expected if B. magnifica and B. soplaensis were sexes of the same species.

The body size, antennal structure and venation of the two species of Buccinatormyia are substantially distinctive from each other, such that we are confident these are not two sexes of the same species. It seems astonishing that two species of this rarely fossilized fly were captured in the same piece of amber. Perhaps copious resin exuded in close proximity to the plant reproductive structures that these flies visited for nectar.

The following key to the genera of Zhangsolvidae is based mainly on wing venation. Antennal structure profoundly differs among some groups, but unfortunately this is ambiguous in Zhangsolva and for Cratomyia macrorrhyncha the antennae are incompletely known. 


\section{Key to the genera of Zhangsolvidae}

1. $M_{1}$ and $M_{2}$ diverging from a portion of $\mathbf{M}_{1+2}$ distad to

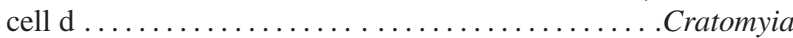
(two species: compressions, Aptian, Crato Formation, Brazil)

$-\mathrm{M}_{1}$ and $\mathrm{M}_{2}$ diverging directly from cell $\mathrm{d} \ldots \ldots \ldots \ldots \ldots 2$

2. Rs diverging from $R_{1}$ significantly basal to the middle of the wing. Crossvein $\mathrm{r}-\mathrm{m}$ about $3 \times$ shorter than basal section of vein $\mathrm{M}_{1+2}$. Cell $\mathrm{d}$ about $3 \times$ longer than wide ........ Zhangsolva (one species: compression, Barremian?, Laiyang Formation, China)

- Rs diverging from $R_{1}$ near the middle of the wing. Crossvein $\mathrm{r}-\mathrm{m}$ as long as basal section of vein $\mathrm{M}_{1+2}$ or slightly longer/shorter. Cell $\mathrm{d}<2.5 \times$ longer than wide......... 3

3. Antenna with six articles, with minute apical stylus. Stem of Rs long, several times the $\mathrm{r}-\mathrm{m}$ crossvein length............

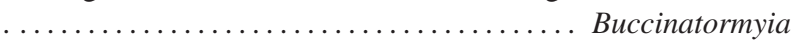
(two species: amber inclusions, Albian, El Soplao, Las Peñosas Formation, Spain)

- Antenna with five articles, without minute apical stylus. Stem of Rs short, shorter than $\mathrm{r}-\mathrm{m}$ crossvein ......... Linguatormyia (one species: amber inclusion, Upper Albian-Lower Cenomanian, Hukawng Valley, Myanmar)

\section{Relationships and phylogenetic analysis}

According to Mazzarolo \& Amorim (2000), Zhangsolvidae (their Cratomyiidae) is the sister group to (Xylomyidae + Stratiomyidae), with Pantophthalmidae the sister group to these three families. That hypothesis was based on 11 characters, all except one being wing venation. With Zhangsolvidae now known in amber, the preservation of critical, minute characters allows an analysis of relationships of these interesting flies with substantially more data.

A total of 52 morphological characters were scored for 33 ingroup taxa (including 11 Cretaceous species) and two outgroups (Symphoromyia sp. [Rhagionidae] and Xylophagus sp. [Xylophagidae]). Several larval characters are quite informative of relationships, such as the presence of calcareous warts and three instars (Xylomyidae + Stratiomyidae) (Woodley, 1986, 1995). However, we did not include immature characters because these are unknown for many extant and all fossil taxa. Among the 52 characters, 15 are from the head (including antennae and mouthparts), 10 from the thorax and legs, 15 from the wing venation, 5 from the pre-genital abdomen, and 7 from the male and female terminalia. Woodley $(1986,1995)$, Mazzarolo \& Amorim (2000) and Yeates (2002) were sources for many of the characters, but 19 characters presented here are newly proposed. Cratomyia, which is extremely well preserved as mineralized 3D replicas in limestone, had twice the number of missing characters as did the two amber genera.

Characters used in the phylogenetic analysis are the following:

\section{Head}

1. Shape of vertex: (0) ocellar area only slightly raised, without lateral concavities; (1) head vertex with dorsal ocellar tubercle, concave on each side of tubercle (Figs 11A, 14A).

2. Facial structure: (0) face flat or slightly bulging; (1) face with small to large, conical tubercle, sometimes horn-like and larger in females (Fig. 14A, C).

3. Inner margin of eye around or just dorsal to base of antenna: (0) no emargination; (1) slight emargination present (Figs 11A, 14B).

4. Pilosity of frons: (0) frons bare or with sparse pilosity; (1) frons with distinct pilosity (Fig. 14B).

Antenna

5. Number of flagellomeres: (0) eight (Fig. 15A, B); (1) five or four (Figs 5A, 8A, 10B); (2) two.

6. Sexual dimorphism of apical flagellomere: (0) male similar to female; (1) apical flagellomere slender and styliform in males (Fig. 14C).

7. Presence/absence and sensillar structure of foveae on the flagellum: (0) foveae absent; (1) foveae present and well developed with each fovea having a single, digitiform sensillum basiconicum (Fig. 15); (2) foveae well developed, with each sensillum basiconicum having multiple $(\geq 2)$ digitiform processes (Fig. 15C).

8. Antennal stylus: (0) absent, or apical flagellomere not highly differentiated from preapical one; (1) present, minute and conical (Figs 8A, 9G, 14A, 15A, D-G).

Mouthparts

9. Proboscis structure: (0) proboscis short, not extended much beyond palps; (1) proboscis elongate, one to several times length of the head (Figs 1-6, 10-12).

10. Size of labellum: (0) labellum typical of most Brachycera, extended laterally approximately to palpal margins; (1) labellum small, proboscis short in proportion to palps and head (Fig. 14C).

11. Palp structure: (0) palp short, length $<5 \times$ the width; setose, but setae rarely like a bottle-brush; (1) palp long, length $>10 \times$ width; with very long, erect setae at the base (Figs 5C, 11C).

12. Cuticular structure of palp: (0) without fine wrinkling; (1) palpomeres with fine, irregular, transverse annulations/wrinkling at proximal ends (Fig. 14C).

13. Development of adult mouthparts (labellum, labium, palps): (0) well developed, fully functional; (1) highly reduced to vestigial (Fig. 14D).

Eyes

14. Male eyes: (0) holoptic (Fig. 14C, D); (1) dichoptic (Fig. 14B).

15. Eye vestiture: (0) absent, very sparse, or so minute as to be discernible under light microscopy at ca. 100x (Fig. 14A-D); (1) with dense, long pilosity (setal length greater than diameter of eye facets). 
Thorax

16. Post-tegula pilosity: (0) absent; (1) present.

17. Area surrounding metathoracic spiracle: (0) bare; (1) with tuft of fine hairs ventrally (Fig. 16C).

18. Scutellar spines: (0) absent; (1) present.

19. Bulla-like structure ventral to base of wing: (0) absent; (1) present (Fig. 16C).

20. Probasisternum structure: (0) probasisternum of unmodified size, distinct from prosternum and cervical sclerites (Fig. 11B); (1) probasisternum large, fused with surrounding sclerites.

Legs

21. Number of protibial spurs: (0) none; (1) one.

22. Number of mesotibial spurs: (0) none; (1) one (Fig. 16D, F); (2) two (Fig. 16E).

23. Number of metatibial spurs: (0) none; (1) one; (2) two (Fig. 7C).

24. Metafemur with lateroapical spine: (0) absent; (1) present.

25. Ornamentation of ventral surface of metafemur: (0) without spines or denticles; (1) with longitudinal series of black denticles.

Wing

26. Wing membrane: (0) without fine wrinkling; (1) with a series of fine wrinkles along the wing margin that parallel the terminal sections of the veins; (2) with fine, irregular pleating/wrinkling that covers the entire wing; wrinkles without common orientation (Fig. 13C).

27. Vein C: (0) circumambient (Fig. 13C); (1) ending at or slight past apex of wing (e.g. at apex of $\mathrm{R}_{5}, \mathrm{M}_{1}$, or $\mathrm{M}_{2}$ ) (Fig. 8B); (2) ending before apex of wing, sometimes considerably so (e.g. at apex of $\mathrm{R}_{4}, \mathrm{R}_{4+5}$, or between these and the wing tip) (Fig. 13B).

28. Basal branching of vein R: (0) Rs branching off R basally, in proximal half of wing; (1) Rs branching off $\mathrm{R}$ distally (stem of Rs short), i.e. Rs diverging from $\mathrm{R}_{1}$ near the middle of the wing.

29. Relative length of vein $\mathrm{R}_{1}$ : (0) long, approximately $0.40 \times$ length of $\mathrm{R}$ (=base $+\mathrm{R}_{1}$ ) and higher (Fig. 13A, C, D); (1) short, from 0.15 to $0.30 \times$ length of R (Fig. 13B).

30. Orientation and structure of vein $R_{4}$ : (0) short, significantly diverging from $\mathrm{R}_{5}$; (1) long, curved only at base (i.e. nearly parallel to $\mathrm{R}_{5}$ ).

31. Apices of veins $R_{4}$ and $R_{5}$ : (0) anterior to the wing tip or $\mathrm{R}_{5}$ posterior to the wing tip (Figs $8 \mathrm{~B}, 13 \mathrm{~B}, \mathrm{D}$ ); (1) encompassing the wing tip (Fig. 13C).

32. Costalization of radial veins (i.e. veins shortened, crowded near anterior portion of costal vein): (0) absent; (1) present (Fig. 13B).

33. Structure of vein $M_{1}$ : (0) vein barely curved or straight (Fig. 13B); (1) vein slightly arched (Fig. 13A, C); (2) vein strongly arched (Figs 8B, 13D).
34. Thickness of base of vein $\mathrm{M}_{1}$ : (0) vein well developed, no thinner than other $\mathrm{M}$ veins (Figs 7F, 8B, 13A, D); (1) vein base very thin to evanescent where it bisects the basal cell into br and bm cells (Fig. 13B).

35. Apex of vein $\mathrm{M}_{1}$ : (0) distant from wing apex; (1) ending at or very near the wing apex (Fig. 13B); (2) evanescent or incomplete.

36. Divergence of veins $M_{1}$ and $M_{2}$ : (0) directly from cell $d$ (not from a portion of $\mathrm{M}_{1+2}$ distad to cell d); (1) from a portion of $\mathrm{M}_{1+2}$ distad to cell d.

37. Vein $\mathrm{M}_{3}$ : (0) present; (1) absent (Fig. 13B).

38. Cell $\mathrm{m}_{3}$ shape (only applicable in those taxa where $\mathrm{M}_{3}$ is present): (0) cell open apically; (1) cell closed (i.e. $\mathrm{M}_{3}$ and $\mathrm{CuA}_{1}$ meeting before wing margin) (Fig. 13A, C, D).

39. Proportions of discal cell: (0) cell long and narrow, approximately $0.20 \times$ the wing length and greater (Fig. 13A); (1) cell short and broad (Fig. 13D).

40. Apical shape of cell cup: (0) acute (Figs 8B, 13A, C, D); (1) truncate (apical section $\mathrm{CuA}_{2}$ nearly perpendicular to $\mathrm{A}_{1}$ ) (Fig. 13B).

Abdomen

41. Structure of female cerci: (0) cerci not separated by tergite $X$; (1) cerci separated by tergite $X$.

42. Tergal grooves: (0) absent; (1) present, deep and transverse on tergites II-VI preapically (Fig. 16A, B).

43. Abdominal muscle plaques: (0) scattered, in an irregular line oblique to the tergal margins (Figs 7H, 16A); (1) parallel to the tergal sulci/margins (Fig. 16B).

44. Development of tergites I and II: (0) well developed (at least tergite II), as in tergites III-VI; (1) reduced, with membranous areas; abdomen held raised.

45. Development of tergites VI and VII: (0) abdominal segments VI and VII slightly smaller than preceding segments, but not reduced; (1) abdominal segments VI and VII clearly reduced in size (i.e. five major segments present).

46. Spermathecal number: (0) three; (1) two.

47. Shape of ejaculatory apodeme: (0) generally elongate, laterally compressed; (1) a concave plate.

48. Sperm pump: (0) structure generalized; (1) uniquely modified.

49. Hypandrial fusion: (0) hypandrium articulates with but not fused to gonocoxites; (1) hypandrium fused to gonocoxites.

50. Paramere structure: (0) parameres well developed, not fused or hood-like; (1) parameres fused, small, not hood-like

51. Size of male sternite VIII: (0) sternite a recognizable, plate-like sclerite; (1) sternite reduced or absent.

52. Phallus structure: (0) phallus a simple tube; (1) phallic complex trifid.

The TNT analysis of the matrix presented in Table 1 yielded 270 most-parsimonious trees of 101 steps. A consensus topology 

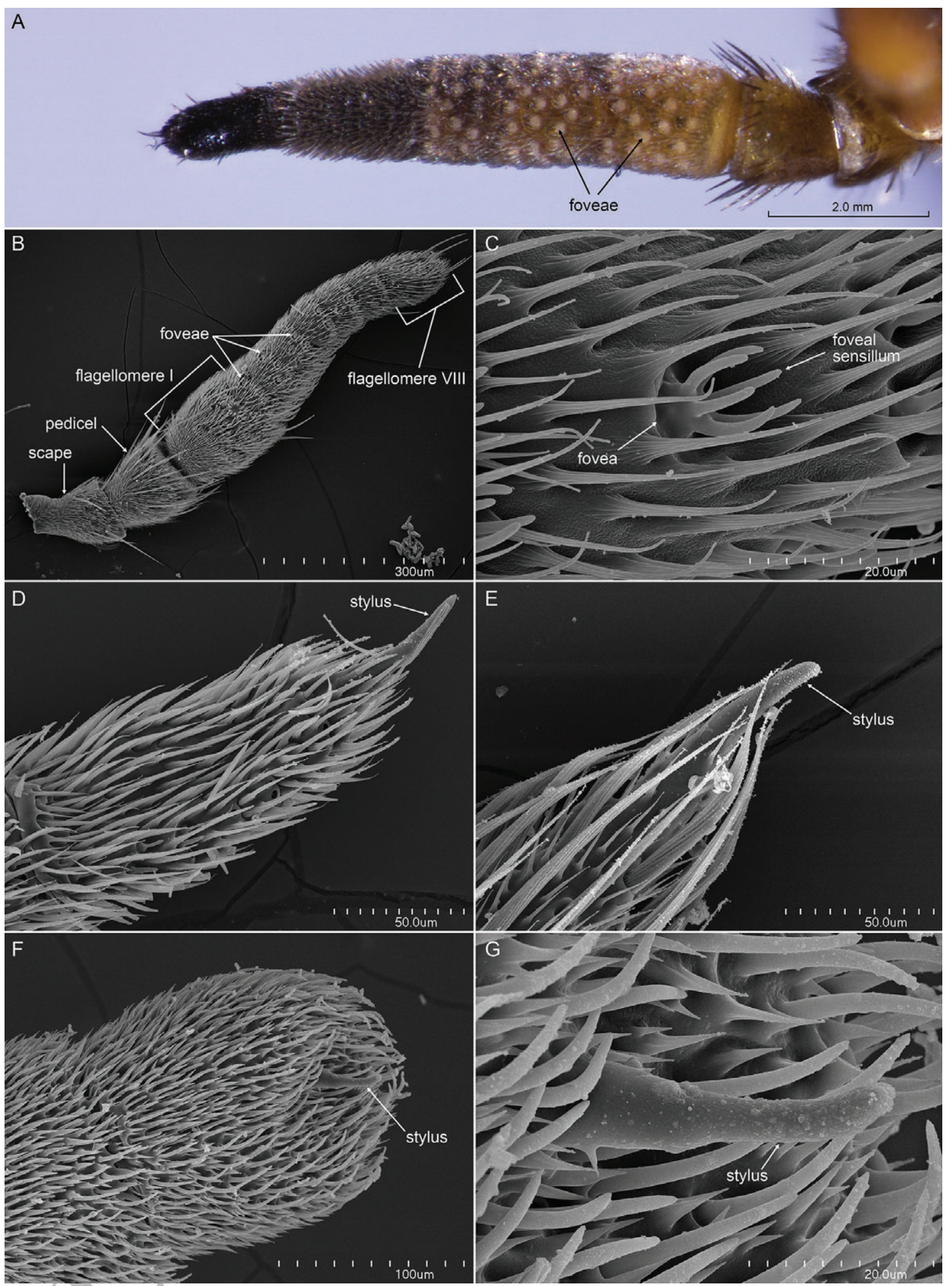

Fig. 15. Antenna of recent basal Brachycera, showing details of the foveae and stylus. (A) Photomicrograph; (B-G) scanning electron micrographs. (A) Artemita sp. (Stratiomyidae), lateral view of entire antenna; (B, C) Allognosta fuscitarsis (Stratiomyidae), showing entire antenna (B, in lateral view) and detail of fovea with a multidigitate sensillum (C); (D) tip of antenna of Solva sp. (Xylomyidae), showing minute stylus; (E) tip of antenna of Xylomyia pallidifemur (Xylomyidae), showing minute stylus; (F, G) tip of antenna of Xylophagus reflectans (Xylophagidae), showing apical flagellomere (F) and detail of minute stylus $(\mathrm{G})$. 

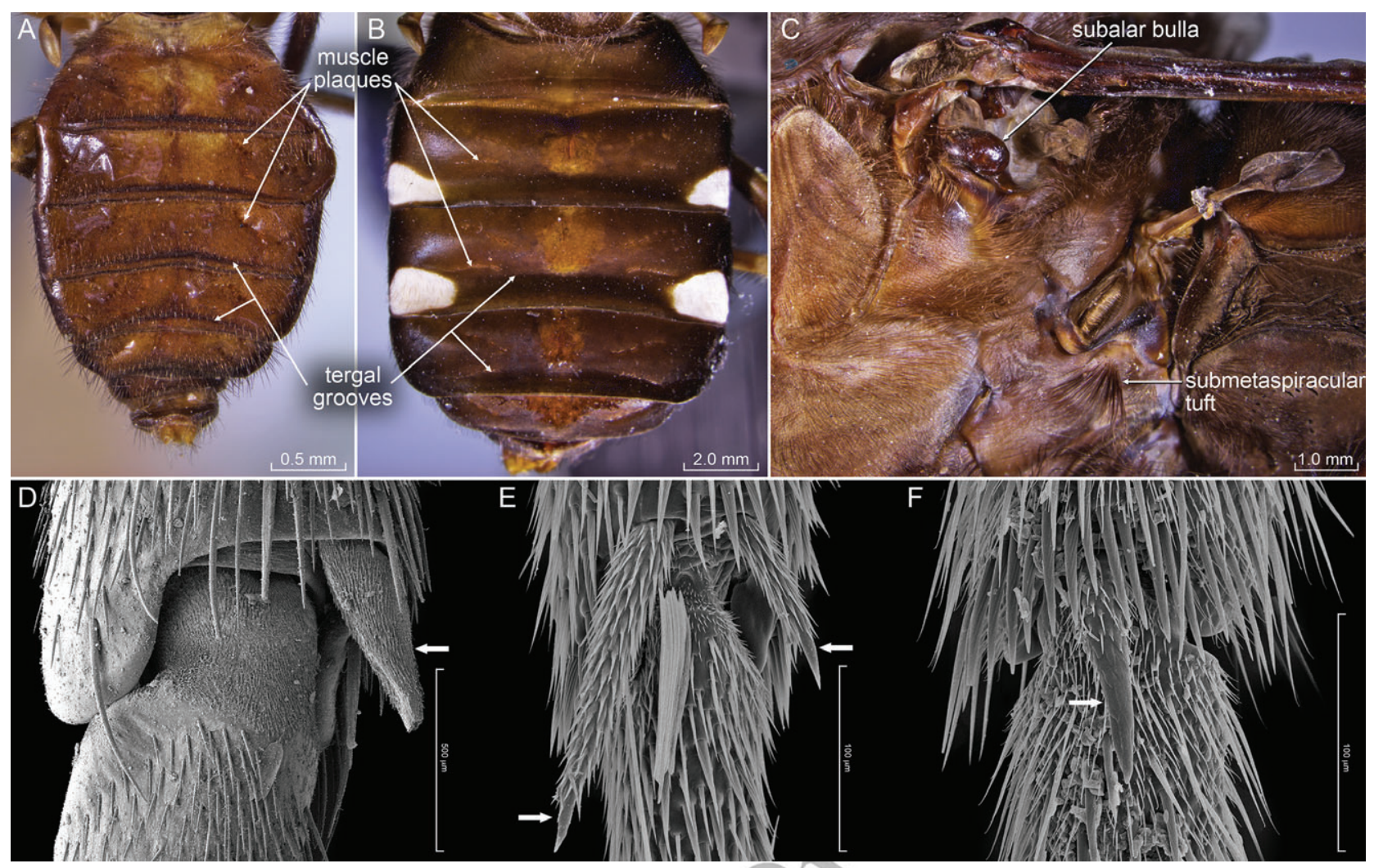

Fig. 16. Thoracic and abdominal characters of recent Stratiomyomorpha. (A, B) Abdomens in dorsal view; (C) portion of thoracic pleura; (D-F) mesotibial spurs (arrows). (A) Allognosta fuscitarsis (Stratiomyidae); (B) Pantophthalmus pictiventris (Pantophthalmidae); (C) Pantophthalmus tabaninus; (D) Pantophthalmus frauenfeldi; (E) Solva sp. (Xylomyidae); (F) Allognosta fúscitarsis (Stratiomyidae).

is shown in Fig. 17 (CI 0.40, RI 0.76), and supports the monophyly for each family: Pantophthalmidae, Xylomyidae, Zhangsolvidae and Stratiomyidae.

This analysis confirms Mazzarolo \& Amorim's (2000) place ment of Zhangsolvidae within the Stratiomyomorpha, a hypothesis based on three wing venation characters: $\mathrm{M}_{3}$ fused to $\mathrm{Cu} \mathrm{A}_{1}$, forming a cell $\mathrm{m}_{3}$ (lost in many Stratiomyidae); $\mathrm{CuA}_{2}$ fused to $A_{1}$ (convergent with other families of Brachycera); and vein $M_{1}$ weakly to strongly arched (unique to stratiomyomorphans, but variable in development and not found in all). Though not known for all species of Zhangsolvidae, at least some of the amber species also share with extant stratiomyomorphans the following characters: (i) two palpomeres, (ii) no protibial spurs (observable only for Buccinatormyia magnifica gen. et sp.n.) and (iii) vein $\mathrm{C}$ ending near the wing apex instead of being circumambient (e.g. in Pantophthalmidae, which is putatively plesiomorphic but could be structurally related to their large size and reinforcement of the wing).

Interestingly, in our analysis the relationships among families in the infraorder and to Xylophagus (Xylophagidae) were unresolved; the most widely accepted hypothesis of stratiomyomorphan relationships is Pantophthalmidae (Xylomyidae + Stratiomyidae) (Woodley, 1986, 1995; Sinclair, 1992; Sinclair et al., 1994; Yeates, 2002; Woodley et al., 2009; Wiegmann et al., 2011). This is undoubtedly due to the absence of larval characters in our matrix. Also, our analysis did not resolve basal relationships within Stratiomyidae. This is somewhat surprising in light of the relationships among extant subfamilies presented by Woodley (1986, 1995), of Parhadrestiinae (Chiromyzinae (Beridinae (Clade 4 [higher] Stratiomyidae))). Although we did recover monophyly of the Parhadrestiinae (including Cretaceogaster), the Chiromyzinae and higher stratiomyids, we did not recover monophyly of the Beridinae. The irresolution in our results is probably due to the inclusion of three Early Cretaceous genera - i.e. Cretoxyla Grimaldi \& Cumming (Xylomyidae, in Lebanese amber), Montsecia Mostovski (Stratiomyidae, in limestone from Spain) and Lysistrata Grimaldi \& Arillo (Stratiomyidae, in Spanish amber) - as well as an undescribed taxon in Late Cretaceous amber from New Jersey (Grimaldi \& Cumming, 1999). These fossils are incomplete, basal, and have some unusual character combinations. The monophyly of Beridinae is best defined by the presence of a deep, transverse furrow on each of the larger tergites; Pantophthalmidae have similar, but more shallow, furrows, as do some stratiomyids in Cretaceous amber that are as yet undescribed (D. Grimaldi, unpublished data).

The analysis does indicate that there are three groups in the Zhangsolvidae: Zhangsolva, Cratomyia and (Linguatormyia + Buccinatormyia), the latter defined by the reduced number of flagellomeres; (Cratomyia cretacica + 


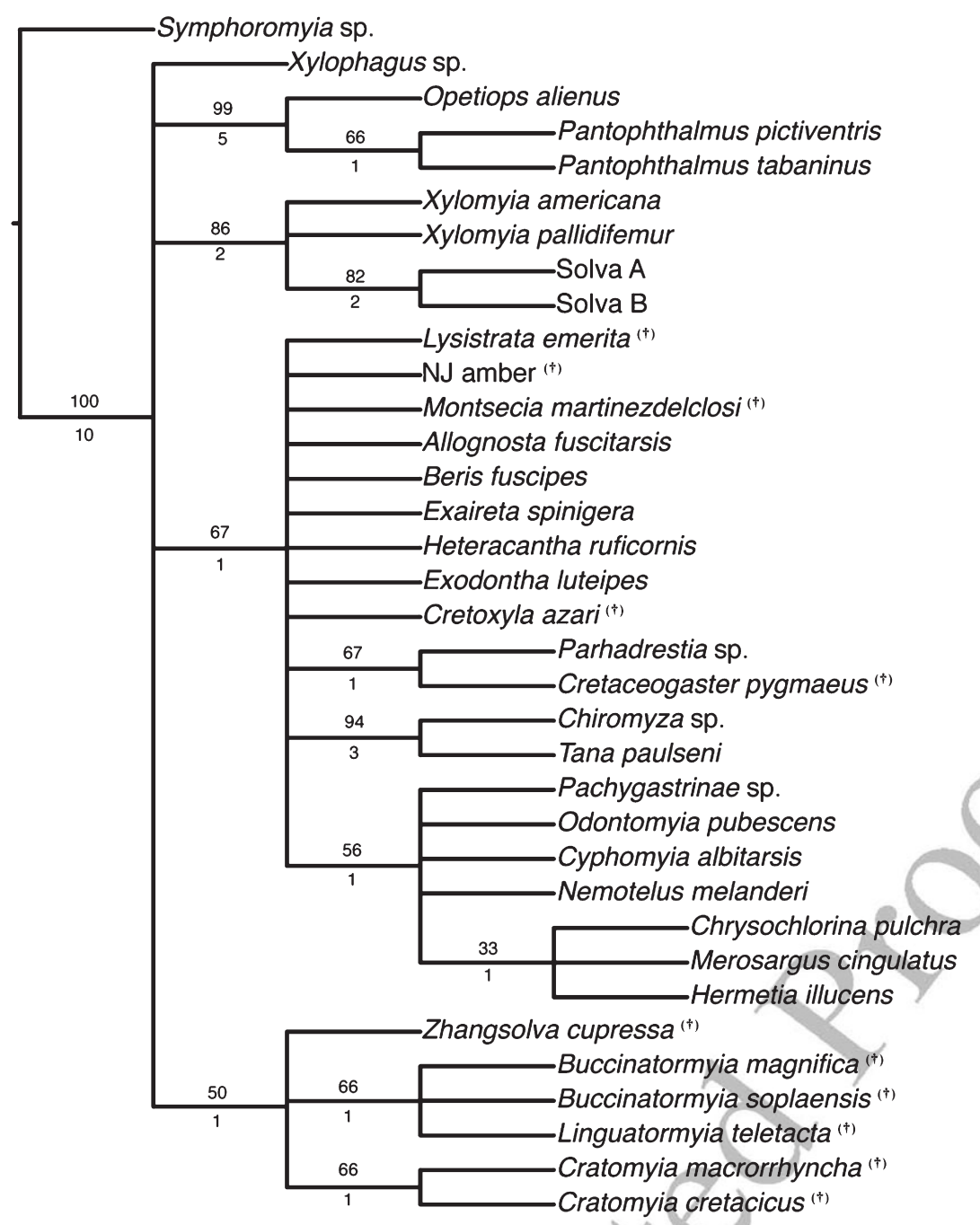

Fig. 17. Consensus cladogram of relationships of recent and fossil Stratiomyomorpha based on morphological characters (see text). Outgroups were Symphoromyia sp. (Rhagionidae) and Xylophagus sp. (Xylophagidae). Taxa marked by $(\dagger)$ are fossils from the Cretaceous.

C. macrorrhyncha) are grouped based on the distinctive stem of $\mathrm{M}_{1+2}$ beyond the cell d. Although we were not able to determine a close relationship of Zhangsolvidae to any family of Stratiomyomorpha, the analysis further substantiates placement in this infraorder. The monophyly of Zhangsolvidae is defined by several features, the most striking being the unique development within Stratiomyomorpha of an elongate proboscis. A similar proboscis has developed convergently in assorted orthorrhaphous Brachycera, i.e. within Acroceridae, Apioceridae, Bombyliidae, Mydidae, Nemestrinidae, Tabanidae and Vermileonidae, where it is always associated with flower-visiting behaviour. As such, the proboscis in Zhangsolvidae has significant evolutionary implications, discussed elsewhere (E. Peñalver et al., in preparation).

\section{Acknowledgements}

We thank the staff of the El Soplao cave in Cantabria (Spain) for curation and access to the Spanish specimens, the enterprise SIEC S.A. and the Government of Cantabria. We are grateful to
Rafael López del Valle for preparing the Spanish specimens and to José Antonio Peñas for making the figure reconstructions. Thanks are due to Sieghard Ellenberger, Kassel (Germany), for providing the Burmese amber specimen for purchase to the AMNH; to Steve Thurston, AMNH, for Burmese amber graphics. This study is supported by the IGME project 491-CANOA 35015, the Spanish Ministry of Economy and Competitiveness project CGL2011-23948/BTE, the National Science Foundation grant 1305066, and by generous funding to the American Museum of Natural History by Robert G. Goelet, Chairman Emeritus of the Board of Trustees. We are grateful for the expert reviews by two anonymous reviewers, which significantly improved the original manuscript.

\section{References}

Borkent, A. \& Grimaldi, D.A. (2004) The earliest fossil mosquito (Diptera: Culicidae), in Mid-Cretaceous Burmese amber. Annals of the Entomological Society of America, 97, 882-888.

Goloboff, P.A., Farris, J.S. \& Nixon, K.C. (2008) TNT, a free program for phylogenetic analysis. Cladistics, 24, 774-786. 
Grimaldi, D.A. \& Arillo, A. (2008) The Tethepomiidae, a new family of enigmatic Cretaceous Diptera. Alavesia, 2, 259-265.

Grimaldi, D.A. \& Cumming, J.M. (1999) Brachyceran Diptera in Cretaceous ambers and Mesozoic diversification of the Eremoneura. Bulletin of the American Museum of Natural History, 239, 1-124.

Grimaldi, D.A., Engel, M.S. \& Nascimbene, P.C. (2002) Fossiliferous Cretaceous amber from Myanmar (Burma): its rediscovery, biotic diversity, and paleontological significance. American Museum Novitates, 3361, $71 \mathrm{pp}$.

Grimaldi, D.A., Arillo, A., Cumming, J.M. \& Hauser, M. (2011) Brachyceran Diptera (Insecta) in Cretaceous ambers, part IV, significant new orthorrhaphous taxa. Zookeys, 148, 293-332.

Krzemiński, W. \& Krzemińska, E. (2003) Triassic Diptera: descriptions, revisions and phylogenetic relations. Acta Zoologica Cracoviensia, 46 (suppl.-Fossil Insects), 153-184.

Mazzarolo, L.A. \& Amorim, D.S. (2000) Cratomyia macrorrhyncha, a Lower Cretaceous brachyceran fossil from the Santana Formation, Brazil, representing a new species, genus and family of the Stratiomyomorpha (Diptera). Insect Systematics \& Evolution, 31, 91-102.

McAlpine, J.F. (1981). Morphology and terminology - Adults. Manual of Nearctic Diptera, Agriculture Canada Monographs, Vol. I (ed. by J.F. McAlpine, B.V. Peterson, G.E. Shewell, H.J. Teskey, J.R. Vockeroth and D.M. Wood) 9-63. Research Branch, Ottawa.

Nagatomi, A. \& Yang, D. (1998) A review of extinct Mesozoic genera and families of Brachycera (Insecta, Diptera, Orthorrhapha). The Entomologists' Monthly Magazine, 134, 95-192.

Najarro, M., Peñalver, E., Rosales, I., Pérez-de la Fuente, R., Daviero-Gomez, V., Gomez, B. \& Delclòs, X. (2009) Unusual concentration of Early Albian arthropod-bearing amber in the Basque-Cantabrian Basin (El Soplao, Cantabria, Northern Spain): palaeoenvironmental and palaeobiological implications. Geologica Acta, 7, 363-387.

Najarro, M., Peñalver, E., Pérez-de la Fuente, R. et al. (2010) A review of the El Soplao amber outcrop, early Cretaceous of Cantabria (Spain). Acta Geologica Sinica (English Edition), 84, 959-976.

Nascimbene, P. \& Silverstein, H. (2000). The preparation of fragile Cretaceous ambers for conservation and study of organismal inclusions. Studies on Fossils in Amber, with Particular Reference to the Cretaceous of New Jersey (ed. by D. Grimaldi), pp. 93-102. Backhuys Publishers, Leiden.

Peñalver, E. \& Delclòs, X. (2010). Spanish Amber. Biodiversity of Fossils in Amber from the Major World Deposits (ed. by D. Penney), pp. 236-270. Siri Scientific Press: Manchester.

Pérez-de la Fuente, R. (2012) Paleobiología de los artrópodos del ámbar cretácico de El Soplao (Cantabria, España). Doctoral Thesis, unpublished, Barcelona University, Barcelona [In Spanish, with English summary].

Pérez-de la Fuente, R., Delclòs, X., Peñalver, E. \& Arillo, A. (2011) Biting midges (Diptera: Ceratopogonidae) from the Early Cretaceous El Soplao amber (N Spain). Cretaceous Research, 32, 750-761.

Ross, A.; Mellish, C.; York, P. \& Crighton, B. (2010). Burmese Amber. Biodiversity of Fossils in Amber from the Major World Deposits (ed. by D. Penney), pp. 208-235. Siri Scientific Press, Manchester.
Shi, G., Grimaldi, D.A., Harlowb, G.E. et al. (2012) Age constraint on Burmese amber based on U-Pb dating of zircons. Cretaceous Research, 37, 155-163.

Sinclair, B.J. (1992) A phylogenetic interpretation of the Brachycera (Diptera) based on the larval mandible and associated mouthpart structures. Systematic Entomology, 17, 233-252.

Sinclair, B.J., Cumming, J.M. \& Wood, D.M. (1994) Homology and phylogenetic implications of male genitalia in Diptera - Lower Brachycera. Entomologica Scandinavica, 24, 407-432.

Stoffolano, J.G., Woodley, N.E., Borkent, A. \& Yin, L.R.S. (1988) Ultrastructural studies of the abdominal plaques of some Diptera. Annals of the Entomological Society of America, 81, 503-510.

Stuckenberg, B.R. (2000) Namamyia, a new genus of Vermileonidae (Diptera) from Namaqualand, with a conspectus of the Southern African genera and an account of their adaptations for anthophily. Annals of the Natal Museum, 41, 181-202.

Szucsich, N.U. \& Krenn, H.W. (2000) Morphology and function of the proboscis in Bombyliidae (Diptera, Brachycera) and implications for proboscis evolution in Brachycera. Zoomorphology, 120, 79-90.

Szucsich, N.U. \& Krenn, H.W. (2002) Flies and concealed nectar sources: morphological innovations in the proboscis of Bombyliidae (Diptera). Acta Zoologica (Stockholm), 83, 183-192.

Val, F.C. (1976) Systematics and evolution of the Panthopthalmidae (Diptera, Brachycera). Arquivos de Zoologia (Sao Paulo), 27, 51-164.

Wiegmann, B.M., Trautwin, M.D., Winkler, I.S. et al. (2011) Episodic radiations in the fly tree of life. Proceedings of the National Academy of Sciences of the United States of America, 108, 5690-5695.

Wilkommen, J. \& Grimaldi, D.A. (2007). 11.20 Diptera: true flies, gnats, and crane flies, The Crato Fossil Beds of Brazil (ed. by D.M. Martill, G. Bechly and R.F. Loveridge, pp. 369-387. Cambridge University Press.

Woodley, N.E. (1986) Parhadrestiinae, a new subfamily for Parhadestria James and Cretaceogaster Teskey (Diptera: Stratiomyidae). Systematic Entomology, 11, 377-387.

Woodley, N.E. (1995) The genera of Beridinae (Diptera: Stratiomyidae) Memoirs of the Entomological Society of Washington, 16, 1-231.

Woodley, N.E. (2001) A World Catalog of the Stratiomyidae (Insecta: Diptera), Myia, Vol. 11. Backhuys Publishers, Leiden.

Woodley, N.E. (2011) A catalog of the world Xylomyidae (Insecta: Diptera). Myia, 12, 485-521.

Woodley, N.E., Borkent, A. \& Wheeler, T.A. (2009). Phylogeny of the Diptera. Manual of Central American Diptera, Vol. I. (ed. by B.V Brown, A. Borkent, J.M. Cumming, D.M. Wood, N.E. Woodley and M. Zumbado), 79-94. National Research Council Press, Ottawa.

Yeates, D.K. (2002) Relationships of the lower Brachycera (Diptera): a quantitative synthesis of morphological characters. Zoologica Scripta, 31, 105-121.

Zhang, J.F., Zhang, S. \& Li, L.Y. (1993) Mesozoic gadflies (Insecta: Diptera). Acta Palaeontologica Sinica, 26, 595-603.

Zherikhin, V.V. \& Ross, A.J. (2000) A review of the history, geology and age of Burmese amber (Burmite). Bulletin of the Natural History Museum, London (Geology), 56, 3-10.

Accepted 9 August 2014 


\section{QUERIES TO BE ANSWERED BY AUTHOR}

IMPORTANT NOTE: Please mark your corrections and answers to these queries directly onto the proof at the relevant place.

\section{Queries from the Copyeditor:}

AQ1. Please confirm if the inserted state name abbreviations are fine for affiliations 3,5 and 6 .

AQ2. please insert manufacturer's name and place of manufacture at first mention)

AQ3. We have treated "Family Zhangsolvidae Nagatomi \& Yang, 1998" as head level 3. Please confirm if this fine.

AQ4. Wilkommen, 2007 has not been included in the Reference List, please supply full publication details.

AQ5. We have removed the two rows here as it is identical to the two header rows given above. Please confirm if its fine.

AQ6. Late: or should this be Upper?

AQ7. We have inserted the city location and name of the publisher for Reference McAlpine, 1981. Please confirm if this is correct.

AQ8. As per the journal style thesis references does not have page range. So we have deleted the page range for reference Pérez-de la Fuente, 2012. Please confirm if is this fine.

AQ9. Please provide the location (city, state/country) of publisher name in the reference Wilkommen and Grimaldi, 2007.

AQ10. is Myia a book series or journal title (or both, as in the two Woodley refs)

AQ11. We have processed Figure(s) 2, 4, 6 and 7, 9 and 10, 14-16 in colour. If these figures are to be published in colour, please fill out CWA form if not yet done. 